Research Article

\title{
Performance of Polypropylene Fiber-Reinforced Solidified Soil
}

\author{
Cheng Hu, ${ }^{1}$ Xingzhong Weng $\mathbb{D}^{2},{ }^{2}$ Cong Liu, ${ }^{3}$ Le Jiang, ${ }^{4}$ Junzhong Liu, ${ }^{5}$ and Wenlei Li ${ }^{6}$ \\ ${ }^{1}$ Troops of 93023, People's Liberation Amy of China, Hulunbuir, China \\ ${ }^{2}$ Department of Airfield and Building Engineering, Air Force Engineering University, Xi'an, Shaanxi 710038, China \\ ${ }^{3}$ Troops of 93361, People's Liberation Amy of China, Shenyang, China \\ ${ }^{4}$ The Military Facilities Construction Bureau, Logistics Department of Air Force Military Region of Beibu, Shenyang 110021, China \\ ${ }^{5}$ Foshan City Transportation Bureau, Foshan, Guangdong 52800, China \\ ${ }^{6}$ Beijing Special Engineering Design and Research Institute, Beijing 10028, China
}

Correspondence should be addressed to Xingzhong Weng; wxz2626@sina.com

Received 8 August 2020; Revised 17 February 2021; Accepted 22 March 2021; Published 8 April 2021

Academic Editor: Loke Foong

Copyright (c) 2021 Cheng $\mathrm{Hu}$ et al. This is an open access article distributed under the Creative Commons Attribution License, which permits unrestricted use, distribution, and reproduction in any medium, provided the original work is properly cited.

\begin{abstract}
Urgent repair and construction of airstrips is a research hotspot in global airport engineering. Selecting the proper structural materials is a key component of the airstrip repair process. First, with unconfined compressive strength and splitting tensile strength, the fiber length and content of polypropylene (PP) fiber-reinforced solidified soil were optimized. Then, using a scanning electron microscope, the reinforcing mechanism of PP fiber on soil and the influence mechanism of fiber parameters on fiberreinforced soil were discussed and analyzed. Lastly, a full-scale test section was paved, on which static and dynamic loading tests were performed to verify the carrying capacity and deformation characteristics of the full-scale test section. The above research provides a theoretical foundation and data support for the urgent repair and construction of airstrip. Results indicate that PP fiber with length of $12 \mathrm{~mm}$ and fiber content of $0.3 \%$ has optimal performance and economic cost. The reinforcing mechanism of fiberreinforced soil can be summarized to be the effect of a one-dimensional lacing wire and the effect of a three-dimensional network structure. Fibers show two failure modes of pull-out and tensile failure. After 20000 dynamic loading cycles, the stress at the bottom of each structural section varies less, the graded plastic deformation is stable, and the cumulative plastic deformations of the fiber-reinforced soil base, solidified soil base, and cemented soil base pavement structures are $0.83 \mathrm{~mm}, 0.93 \mathrm{~mm}$, and $1.2 \mathrm{~mm}$, respectively. Pavement structure composed of fiber-reinforced solidified soil can meet the load capacity requirements for use in airstrips under the characteristics of time-sensitive application.
\end{abstract}

\section{Introduction}

An airstrip is an airport built hastily in case of emergency (such as war, emergency rescue, and disaster relief) for airplanes' taking off and landing in a short time [1-3]. Considering that airstrips are characterized by quick construction and are designed for short-term urgent use, construction materials should be sourced from existing local materials. Cement and lime as well as other kinds of inorganic binder-stabilized soil may serve as the primary base materials, which can greatly shorten construction time. Relevant research findings indicate that using traditional inorganic binder-stabilized soil alone cannot meet the mechanical requirements for use in airstrip construction [4]. Cement, lime, and other types of traditional inorganic binder-stabilized soil have poor crack resistance, insufficient water stability, and easily undergo brittle failure, which limits their application in airstrip construction and other engineering projects $[1,5]$. At present, studies primarily focus on improving the above defects by adding new curing agent and fiber. The specific method is to remove the surface impurities of the soil to be improved. Then, pour it into the blender and mix it with curing agent, fiber, and other reinforcers. Lastly, treated soil is spread, compacted, and maintained. Numerous studies on new curing agents indicate that compared with traditional curing agents such as 
cement and lime, all the mechanical properties of soil improved by new curing agent are improved. However, the compressive strength, tensile strength, cracking resistance, and durability of new curing agent improved soil cannot be enhanced simultaneously. Additionally, water stability of new curing agents improved soil is still poor [1, 6-10]. Therefore, reinforcing soil using a curing agent only cannot meet the requirements for airstrip use. Incorporating fiber into the soil is an effective method for improving the soil mechanical properties. At present, fibers used for reinforcement mainly include plant fiber and synthetic fiber. Plant fiber includes corn fiber, sisal fiber, bagasse fiber, and palm fiber [11-14]. Synthetic fiber includes polypropylene (PP) fiber, glass fiber, basalt fiber, and waste tire textile fiber [15-18]. Among synthetic fiber, PP fiber has high strength as well as good wear resistance, corrosion resistance, and resilience. Therefore, it has attracted much attention in various geotechnical applications. The main indices for evaluating soil performance include unconfined compressive strength (UCS) and splitting tensile strength (STS) [18]. The incorporation of PP fiber can effectively enhance the unconfined compressive strength, tensile strength, and water stability of soil. However, the reinforcing effect is related to fiber parameters and reinforcing objects [18-22]. For example, Soğanci found that PP fiber can enhance the UCS and ductility of expansive soil and when fiber content is $1 \%$, fiber-reinforced expansive soil UCS is biggest. Kumar et al. found that UCS and STS of fiber-reinforced clay always increase with the increase of fiber content within the range of $0 \sim 1.6 \%$. Correia et al. found that the addition of a low quantity of fiber to the stabilized soft soil originates a decrease in the stiffness, compressive, and direct tensile strength, because the impact of the addition of fiber on the strength depends on the strain mechanism used in each test.

At present, studies are primarily focused on fiberreinforced cement stabilized soil. Few studies focus on composite reinforcement combining new curing technology, traditional curing technology, and reinforcement technology. Even less research is conducted on composite reinforcement applications in the rapid construction of emergency projects such as airstrips. At present, most of the studies on fiber-reinforced soil are primarily focused on minor indoor test pieces, which is different from practical uses of fiber-reinforced soil. Therefore, it is necessary to conduct full-scale tests for further study. Indoor full-scale tests can simulate the real case to a large extent $[1-3,23,24]$, which can effectively verify the results of small indoor test pieces, and the difficulty in verification is relatively low. Therefore, first in this paper, a test was conducted on smallsized indoor test pieces to study UCS and STS of PP fiberreinforced solidified soil and comprehensively determined the optimal fiber specifications and dosage. Then, using scanning electron microscope (SEM), the reinforcing mechanism of fiber-reinforced soil and the influence mechanism of fiber parameters on fiber-reinforced soil were discussed and analyzed. Lastly, a full-scale test section was paved, on which static and dynamic loading tests were conducted to verify the bearing capacity and deformation characteristics of the full-scale test section. The test results in this paper can provide a theoretical basis for the practical construction of emergency airports.

\section{Materials and Method}

2.1. Materials. The soil for the test is silt taken from Dandong area in China, with the grading curve shown in Figure 1. The liquid-plastic limit combined test was carried out to measure the liquid limit, plastic limit, and plasticity index, which are $46.4 \%, 27.8 \%$, and 18.6 , respectively. The cement is ordinary Portland cement, with a content of $6 \%$. The Environment Friendly Share (EFS) soil-curing agent is an ionic environmentally-friendly soil-curing agent, with a content of $0.5 \%$. Cement-solidified soil is called cemented soil, and the soil reinforced jointly by cement and EFS is referred to as solidified soil. Fiber-reinforced solidified soil is called fiberreinforced soil. The PP fiber used in the test has four sizes, including $6 \mathrm{~mm}, 12 \mathrm{~mm}, 19 \mathrm{~mm}$, and $24 \mathrm{~mm}$ (Figure 2). The fiber content (calculated by the percentage of dry soil mass) is $0.1 \%, 0.2 \%, 0.3 \%, 0.45 \%, 0.6 \%$, and $0.8 \%$. The optimum moisture content and the maximum dry density of the solidified soil ( $6 \%$ cement $+0.5 \%$ EFS) were $14.12 \%$ and $1.92 \mathrm{~g} / \mathrm{cm}^{3}$, which were obtained by the compaction test [25].

2.2. UCS and STS Tests. The UCS test was carried out according to the specification [25] using the apparatus shown in Figure 3. Stress-strain data were collected once for every 8 specimens. The specimens are cylindrical with a dimension of $\Phi 50 \times 50 \mathrm{~mm}$, with 6 specimens in each group. Specimens were cured for $7 \mathrm{~d}$ after preparation. In the first 6 days, the specimens were placed in a curing box for standard curing (with the temperature of $20 \pm 2^{\circ} \mathrm{C}$ and a relative humidity over 95\%). On the $7^{\text {th }}$ day, the specimens were taken out and cured in water for $24 \mathrm{~h}$ at a constant temperature $\left(20 \pm 2^{\circ} \mathrm{C}\right)$.

The STS test was carried out according to the specification [26]. Its sample preparation method and test instrument are the same with the UCS test. The specimen is placed side between the two battens, and the two battens are strictly aligned (Figure 4). The stress-strain data acquisition method is the same as the UCS test. The splitting tensile strength $\left(R_{i}\right)$ is calculated according to

$$
R_{i}=\frac{2 P}{\pi d h}\left(\sin 2 \alpha-\frac{a}{d}\right),
$$

where $R_{i}$ is the splitting tensile strength of specimens (MPa), $d$ is the specimen diameter $(\mathrm{mm}), a$ is the batten width $(\mathrm{mm}), \alpha$ is the center angle of batten $\left(^{\circ}\right)$, and $h$ is the specimen height $(\mathrm{mm})$

In the STS test, $d$ is $50 \mathrm{~mm}, a$ is $6.35 \mathrm{~mm}$, and $\alpha$ is $80^{\circ}$. There is a certain error in specimen height when forming specimens, so specimen height is the measured value. By substituting the above parameters into equation (1), the final calculation formula of splitting tensile strength can be obtained:

$$
R_{i}=0.012526 \frac{P}{h} .
$$




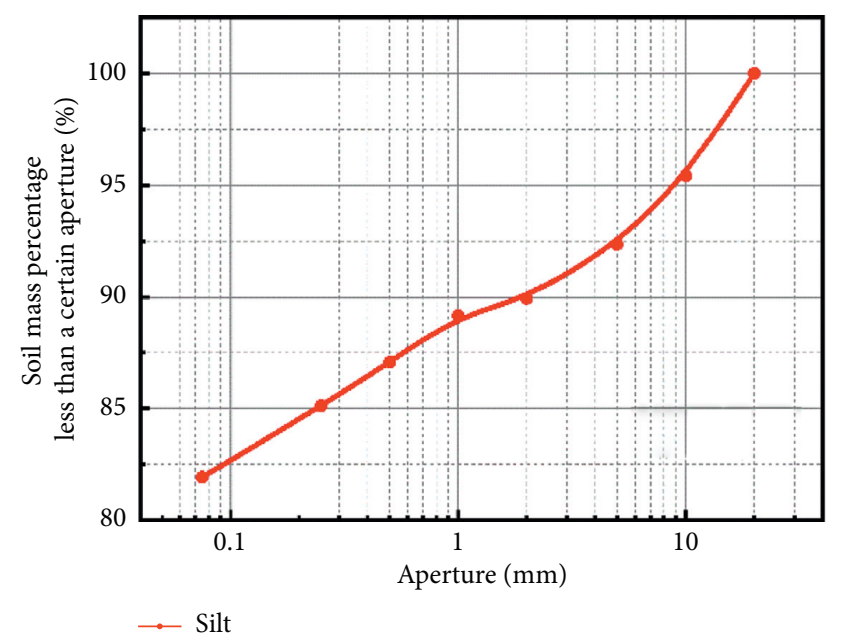

FIgURE 1: Grading curve of soil samples.

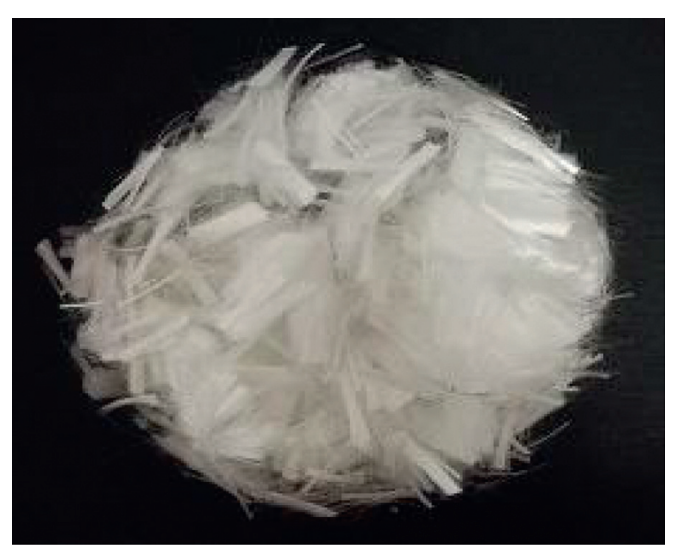

FIgURE 2: PP fiber.

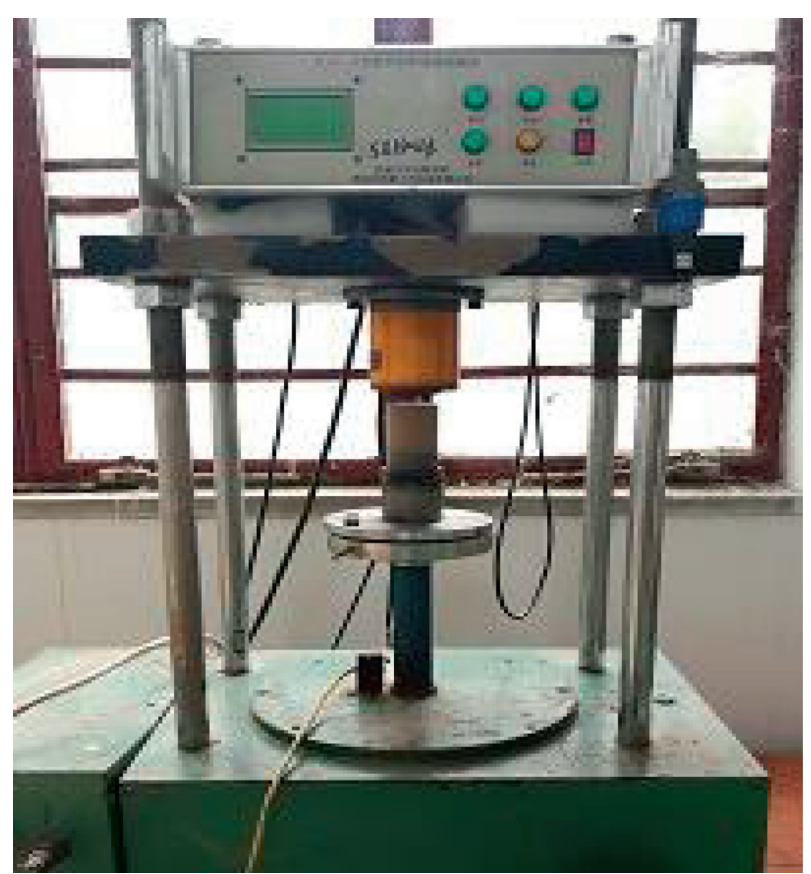

FIGURE 3: UCS test procedure.

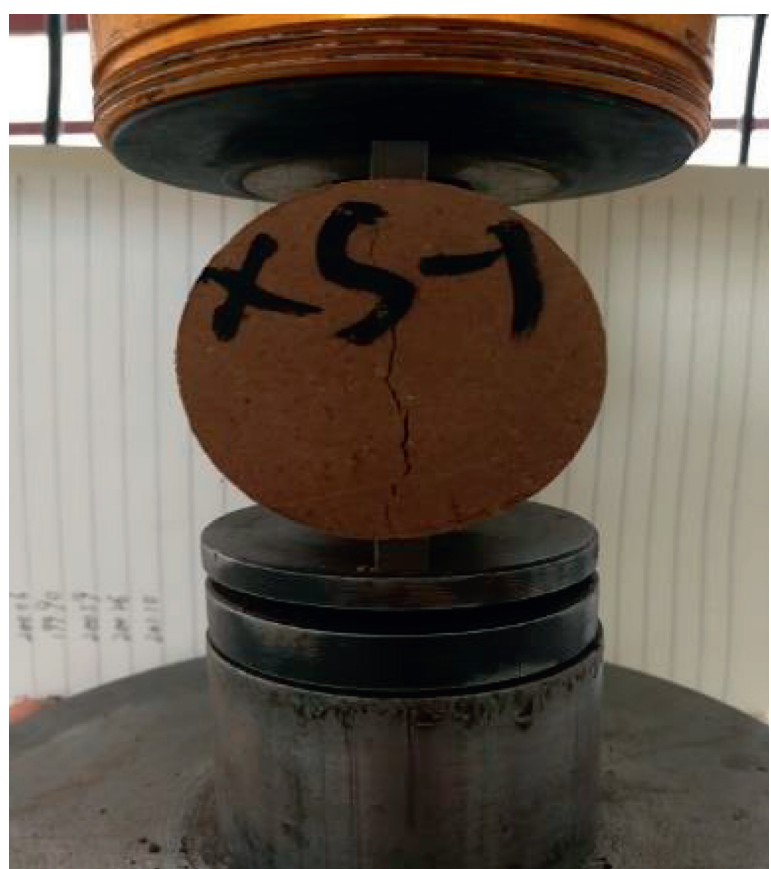

Figure 4: STS test procedure.

2.3. SEM Test. The SEM test was carried out following the guidelines [27] with the TM4000 PLUS desktop scanning electron microscope. A combination of high and low resolution was used to observe the specimens. At present, artificial intelligence has been widely used in the analysis of various properties and mechanisms with good results $[28,29]$. Combined with the actual situation, this paper uses ArcGis software to make a quantitative analysis of the soil voids, which is helpful for further analysis of the strengthening mechanism of fiber-reinforced solidified soil.

2.4. Loading Test on the Full-Scale Section. The bearing capacity and fatigue deformation characteristics of the structural layer were verified under static and dynamic loading. The structural layer models included glass fiberreinforced plastic (GFRP) pavement, base, subbase, and compacted soil base.

2.4.1. Paving the Test Section. The overall dimensions of the full-scale section are $6000 \mathrm{~mm} \times 4000 \mathrm{~mm} \times 650 \mathrm{~mm}$. Half of the base layer was paved using GFRP pavement. The full section is divided into 6 typical structural sections, with dimensions of $2000 \mathrm{~mm} \times 2000 \mathrm{~m}$ (Figure 5(a)). All dimensions in Figures 5 and 6 are in $\mathrm{mm}$. From top to bottom successively lie the base course, subbase course, and compacted soil base (Figures 5(b) and 5(c)). The compacted soil base and subbase course are composed of soil and $6 \%$ cemented soil, respectively. The base course is divided into three sections from left to right, namely, $6 \%$ cemented soil, $6 \%$ cement $+0.5 \%$ e ES solidified soil, and $6 \%$ cement $+0.5 \%$ o EFS $+0.3 \%$ PP fiber-reinforced solidified soil.

The full-scale test section was constructed in five steps: filling and compacting soil base, subbase construction, base 


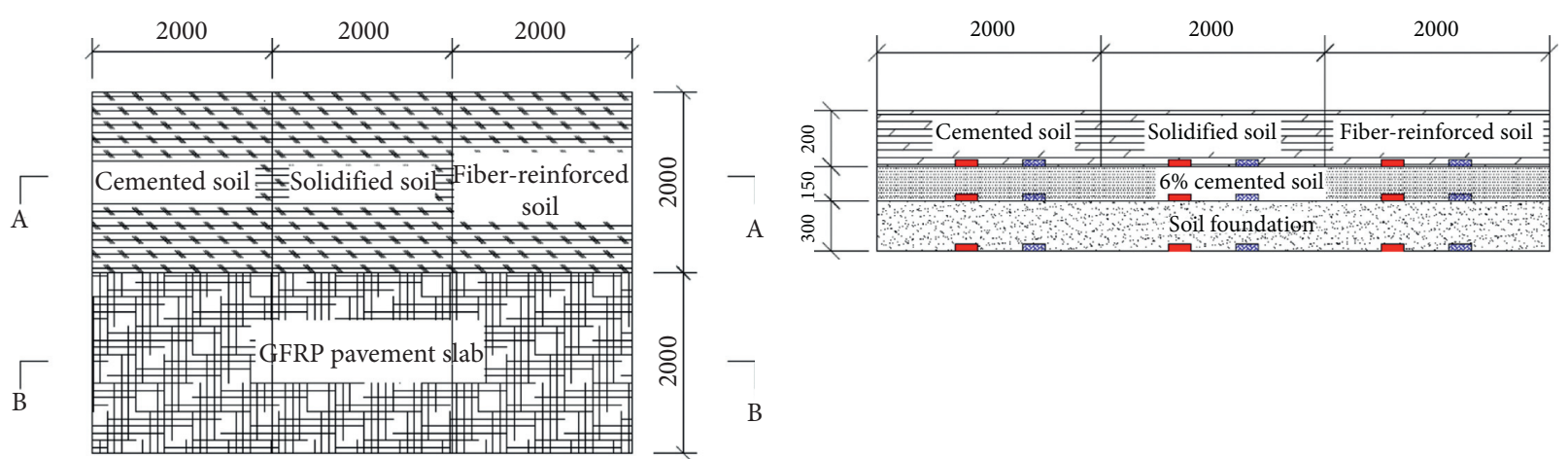

(a)

(b)

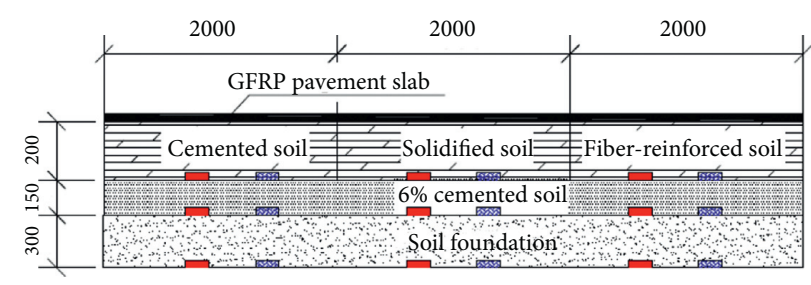

(c)

Figure 5: Size chart of the full-scale test section. (a) Ichnography. (b) A-A profile. (c) B-B profile.

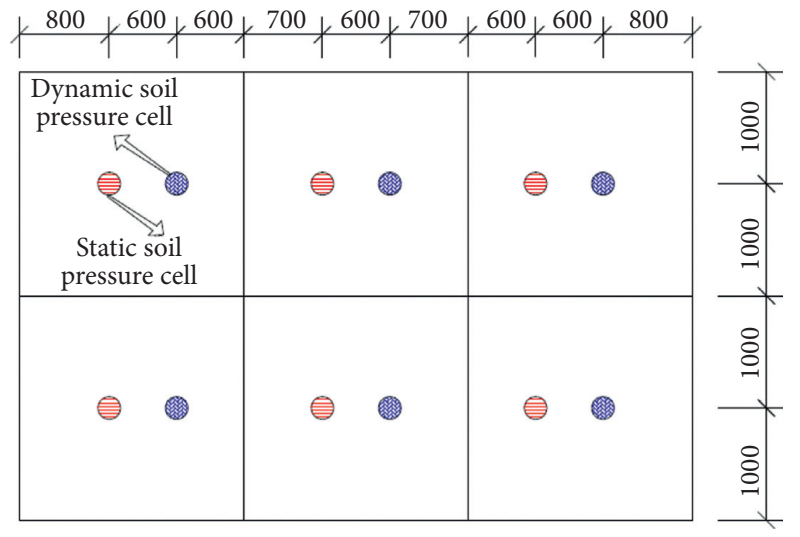

FIgURE 6: Floor plan of pressure cells.

construction, embedding sensors, and laying the GFRP pavement. Dynamic pressure cells and static pressure cells were primarily used to study the variation of stress and deflection of the base, subbase, and compacted soil base under static and dynamic loads. The specific location of the cells is shown in Figures 5(b), 5(c), and 6, and the pressure cells shown in the Figures 5(b), 5(c), and 6 were a schematic diagram, not their actual size. During the test, digital dial gauges were set up at $15 \mathrm{~cm}, 30 \mathrm{~cm}, 50 \mathrm{~cm}$, and $75 \mathrm{~cm}$ from both ends of the loading point to the bearing plate. The dial gauges were connected to computer through the conversion instrument, and data were collected once every 1,000 loading times. After the full-scale section structure reaches the age, its resilience modulus was measured. Then, static and dynamic loading was carried out on the full-scale section structure at the age of 14 days to verify the carrying capacity and deformation characteristics of the full-scale test section structure. The specific loading method will be introduced in Section 2.4.2.
2.4.2. Loading Scheme on the Full-Scale Section. The fullscale test system is primarily composed of a (1) $200 \mathrm{~L}$ dual pump oil source, (2) hydraulic-servo control, (3) water circulating tube type cooling system, (4) hydraulic rubber tubing, (5) actuator, (6) displacement and pressure sensor, and (7) industrial control computer and control circuit (Figure 7). The test apparatus is a multifunctional automatic fatigue test system, and the maximum actuator load is $800 \mathrm{kN}$, with a load stroke to $200 \mathrm{~mm}$ and loading frequency range from 0.1 to $10 \mathrm{~Hz}$. The loading machine includes a hydraulic-servo actuator installed on the reaction frame; the diameter of the bearing slab is $30 \mathrm{~cm}$, and a rubber pad is placed between bearing slab and the pavement slab to keep the pavement slab in good contact with the slab.

The loading positions are at the locations of the dynamic and static pressure cells (Figure 6). Static loading was carried out using step-by-step loading, starting at 0 and increasing by $10 \mathrm{kN}$ for each grade with a maximum loading value of $150 \mathrm{kN}$. After loading to the predetermined load, the pressure was held for $1 \mathrm{~min}$ before data were recorded. With unloading completed, the data were recorded after $2 \mathrm{~min}$ again for the next round of loading. The waveform for dynamic load is a sine wave, with a maximum load value of $100 \mathrm{kN}$, minimum load value of $1 \mathrm{kN}$, frequency of $1 \mathrm{~Hz}$. Loading times were 20,000. The displacement and pressure were collected once every 1,000 loading times through the dynamic stress-strain meter.

\section{Results and Discussion}

3.1. Test Results and Analysis on UCS and STS. According to the test method in Section 2.2, the UCS and STS of fiberreinforced soil with different fiber lengths and fiber contents are studied. The test results are shown in Figure 8. 


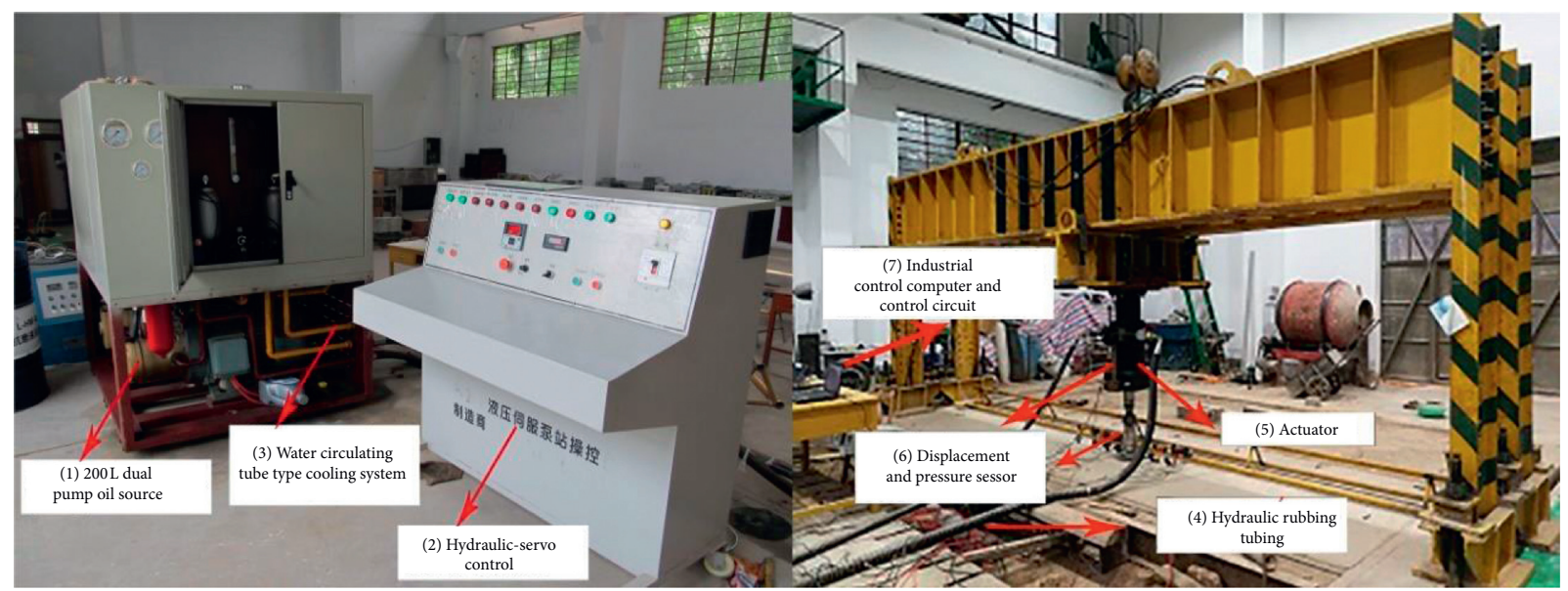

FIGURE 7: YX1200 pavement electrohydraulic servo fatigue test system.

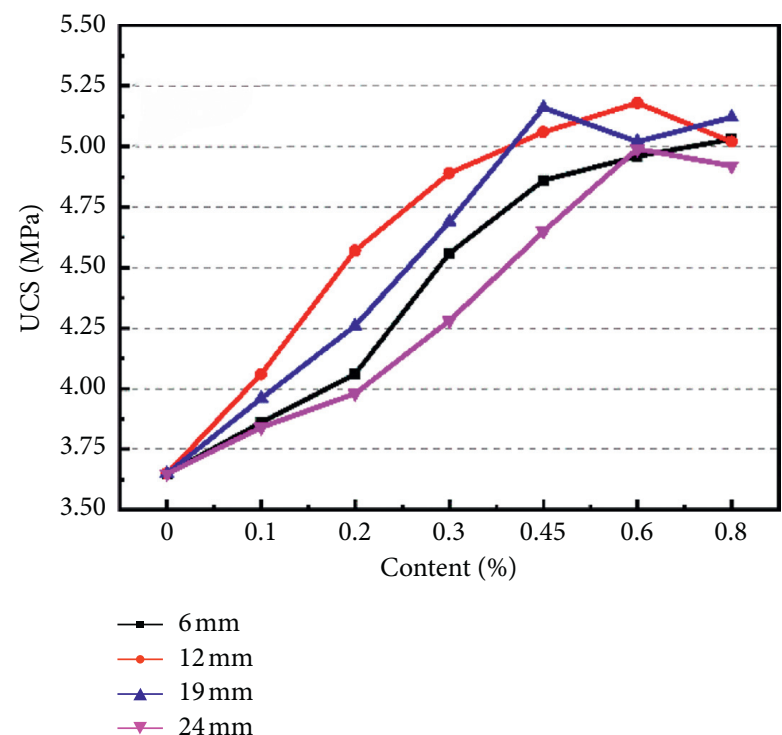

(a)

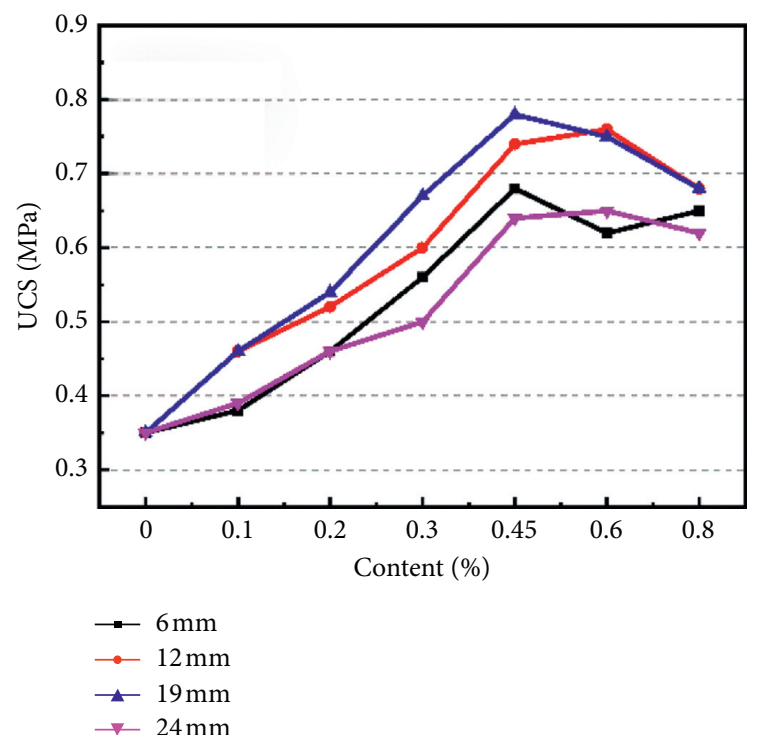

(b)

FIGURE 8: UCS and STS test results of fiber-reinforced soil. (a) UCS. (b) STS.

3.1.1. Effects of Fiber Length and Fiber Content on UCS and STS. UCS results indicate that compared with solidified soil, the UCS of the PP fiber-reinforced soil increased significantly (Figure 8(a)). The UCS of the solidified soil is 3.65 MPa. When PP fiber is incorporated, the UCS reaches $3.84-5.16 \mathrm{MPa}$. The amount of reinforcement is related to fiber length and fiber content. With increasing fiber content, the USC of PP fiber-reinforced solidified soil shows a trend of increasing first and then decreasing. The optimal PP fiberreinforced solidified soil content ranges from $0.45 \%$ to $0.8 \%$. The optimal content of $6 \mathrm{~mm}$ PP fiber is $0.8 \%$. The optimal content of $12 \mathrm{~mm}$ and $14 \mathrm{~mm}$ PP fiber are both $0.6 \%$. And the optimal content of $19 \mathrm{~mm}$ PP fiber is $0.45 \%$. These contents are consistent with the results of Yadav and Tomar $[30,31]$. The UCS of PP fiber-reinforced solidified soil varies with varying fiber length. Overall, the order of the reinforcing effect of PP fiber is $12 \mathrm{~mm}>19 \mathrm{~mm}>6 \mathrm{~mm}>24 \mathrm{~mm}$, which is consistent with the research results from Jiang et al. $[19,21]$. In general, the UCS of reinforced solidified soil with $0.6 \% 12 \mathrm{~mm}$ PP fiber and that of reinforced solidified soil with $0.45 \% 19 \mathrm{~mm}$ PP fiber are best within the all combinations, which are $5.18 \mathrm{MPa}$ and $5.16 \mathrm{MPa}$. Compared with solidified soil, the UCS of fiber-reinforced soil with $0.6 \%$ $12 \mathrm{~mm}$ PP fiber and reinforced solidified soil with $0.45 \%$ $19 \mathrm{~mm}$ PP fiber increase $41.9 \%$ and $41.4 \%$, respectively. From an economic perspective, $0.3 \% 12 \mathrm{~mm}$ PP fiber is recommended in engineering practice. Its UCS is relatively high (4.89 MPa, with an increase of $34.0 \%$ ) and cost is reduced.

The STS of PP fiber-reinforced soil is significantly larger compared with solidified soil. STS of solidified soil is $0.35 \mathrm{MPa}$. After PP fiber is incorporated, the UCS reaches $0.38-0.78 \mathrm{MPa}$. The reinforcement degree is related to the fiber length and fiber content (Figure 8(b)). With increasing 
fiber content, STS increases first and then decreases. The optimal content of $12 \mathrm{~mm}$ PP fiber is $0.3 \%$, while the optimal content of $6 \mathrm{~mm}, 19 \mathrm{~mm}$, and $24 \mathrm{~mm}$ PP fiber is all $0.45 \%$. This result is consistent with Yadav and Tiwari [30] but is slightly different from the results from Gupta and Kumar [19]. For different fiber length, STS of PP fiber-reinforced solidified soil varies and the order of the reinforcing effect of PP fiber is $12 \mathrm{~mm}>19 \mathrm{~mm}>24 \mathrm{~mm}>6 \mathrm{~mm}$, which is slightly different from the rules given by the UCS test results. Reinforced solidified soil with $0.3 \% 12 \mathrm{~mm}$ PP fiber has the highest STS $(5.88 \mathrm{MPa})$, with an increase amplitude of $151.4 \%$. Compared with the UCS of the PP fiber-reinforced soil, the reinforcing effect of PP fiber on the tensile strength of solidified soil is much higher than that on its compressive strength because soil is pressure material and has a relatively higher resistance to compression and a relatively low tensile strength [19].

3.1.2. Analysis of Stress-Strain and Compressive Failure Characteristics. The strength of solidified soil specimens decreases rapidly after reaching the peak, showing the characteristics of brittle failure (Figure 9). When the fiber content is low $(<0.3 \%)$, the strain when the specimen fails is small, so fiber reinforcement cannot be effectively reflected [20]. The PP fiber-reinforced soil is still characterized by significant brittle failure. With increasing fiber content $(0.3 \%-0.8 \%)$, the peak strength increases continuously, and the postpeak strength loss decreases, indicating that the brittle failure of solidified soil was effectively weakened. The peak strength of PP fiber-reinforced soil with $0.6 \%$ fiber is greater than that with $0.8 \%$ fiber, which is consistent with the UCS test results. When there is no reinforcement or less fiber, the crack in the specimen is narrow and long, connects the upper and lower parts, and the upper and lower parts of the specimen maintain a relatively complete cylinder (Figure 10(a)). AS fiber content increases, the number of cracks gradually increases, and cracks become wider. The specimen shape becomes irregular, showing a round platform with the upper wide part and lower narrow part or the middle part expands (a bulging failure) (Figures 10(b)10(d)). This is because in specimens with high fiber content, fiber could confine the soil particles and increase the global stability of the soil mass. Thus, fibers could influence the likelihood of sudden displacement behavior of soil particles under axial loading instead of a more gradual deformation. Therefore, the soil specimen bulged laterally and damaged [32].

3.2. Analysis of the Reinforcing Mechanism of Fiber-Reinforced Solidified Soil Based on SEM. Plain soil (Figure 11) is primarily composed of scattered particles, which interact by means of stacking and occluding. The main particle contact modes include edge-edge and edge-surface. Compared with cement or EFS-reinforced soil, plain soil has higher porosity. After cement and EFS are incorporated (Figure 12), a large number of scattered particles disappear and are turned into solidified cementitious matter. Through stacking, occluding, and cohesion, surface-to-surface contact plays a dominant
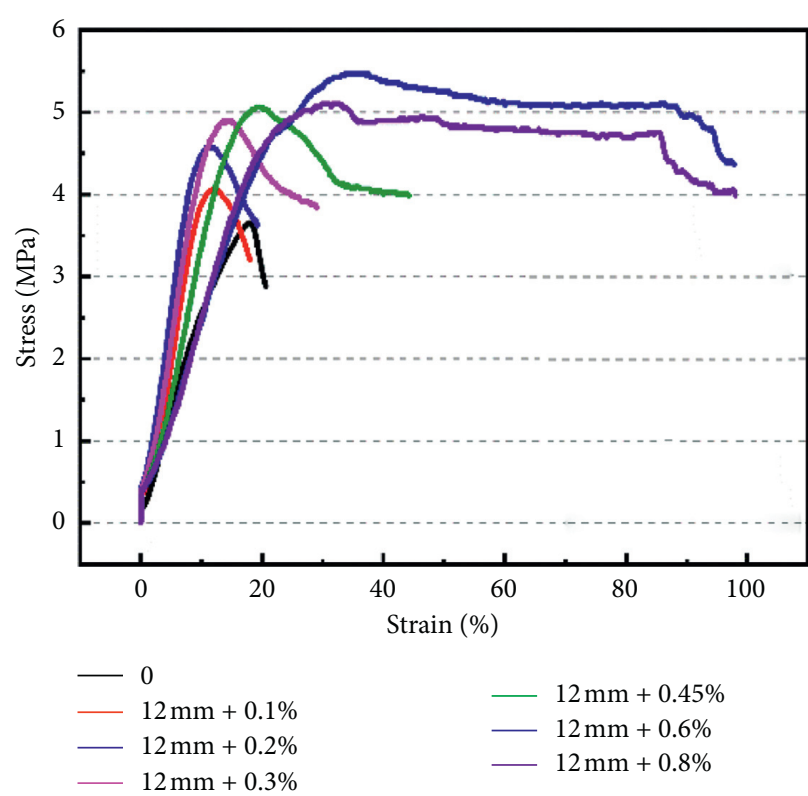

FIGURE 9: Stress-strain curve for the UCS test on fiber-reinforced soil.

role, and soil porosity significantly decreases. Through performing a binarization on SEM images and then using the grid processing kit in ArcGIS to count the number of pixels, the spacing between particles plain soil and solidified soil can be quantitatively analyzed. Tang et al. [33] recommended selecting a smaller threshold $(60-100)$ for quantitatively analyzing the soil microstructure. However, Yiwen [34] believed that when the image is magnified 1,000 times, the porosity can be more reliably determined using a threshold range of 200-220. After analyzing the SEM images with a magnification of 1,800 times and a threshold of $90-100$, the porosity values of plain soil, cement soil, and solidified soil with $6 \%$ of cement $+0.5 \%$ of EFS are determined to be $39.3 \%, 31.8 \%$, and $29.3 \%$, respectively, demonstrating the reinforcing effect of cement and EFS on the strength of soil from a microperspective.

The reinforcing effect of fiber on soil is primarily reflected in two aspects: the one-dimensional lacing wire effect (Figure 13(a)) and the action of the three-dimensional network structure (Figure 13(b)) [35]. A simple description of the effect of one-dimensional lacing wire is as follows: a single fiber or multiple clustered fibers in the same direction are buried deep within the soil and covered by soil particles and hydrated cement products. When the soil bears load, it undergoes deformation and relative sliding between the fiber and soil due to the difference in elastic modulus between the fiber and soil. Under the action of the reinforcement-soil interface, the fiber sliding is limited, so it bears the tensile force, thus sharing the external force. A simple description of the theory regarding the three-dimensional network structure is as follows: it is not difficult to find that a large number of fibers are dispersed randomly forming a network structure (Figure 12(b)). When some of the fibers are subjected to tension, the stable network structure is disturbed and make more fibers are required to disperse the external force. 


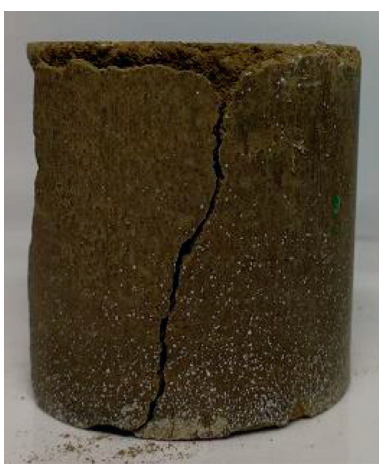

(a)

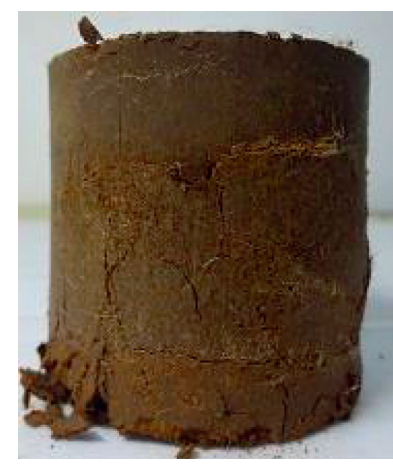

(b)

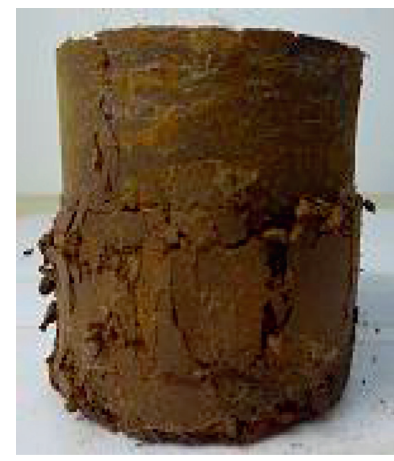

(c)

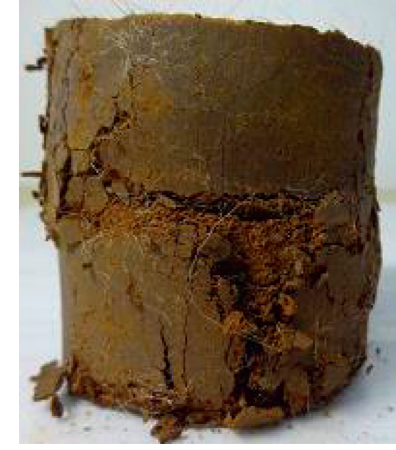

(d)

Figure 10: Typical failure characteristics of fiber-reinforced soil. (a) Unreinforced. (b) $0.1 \%$ fiber content. (c) $0.4 \%$ fiber content. (d) $0.6 \%$ fiber content.

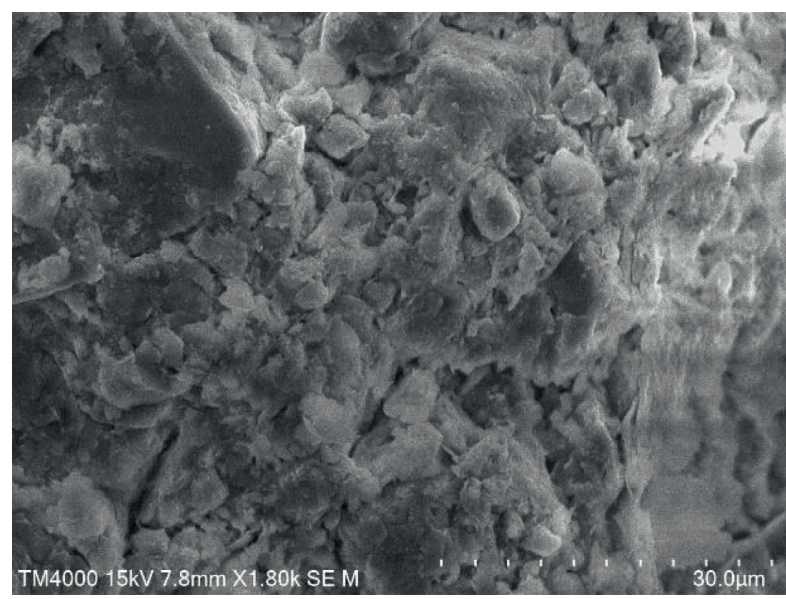

FIGURE 11: Plain soil (1.0k times).

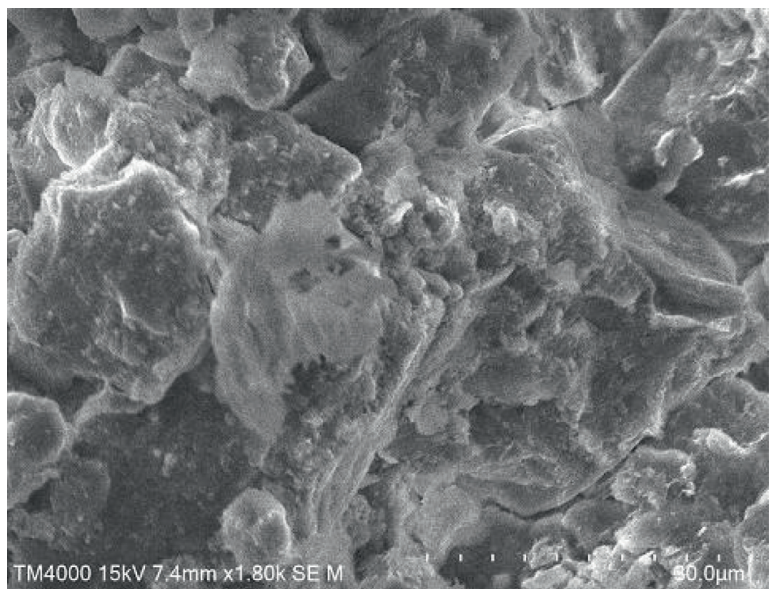

FIgURE 12: $6 \%$ cement $+0.5 \%$ EFS reinforced soil (1.8k times).

Therefore, the network structure spreads the internal load to a wider area and reduces stress concentration, strengthening the soil.

There are two main failure modes of fiber on the reinforcement-soil interface: one is that the fiber is pulled out because the interface force is not sufficient to resist the tension due to the shorter embedding depth of the fiber (Figure 14(a)); the second is that the interface force is greater than the fiber's tensile strength, so the fiber undergoes plastic deformation and tensile failure (Figure 14(b)). These two failure modes are closely related to the magnitude of the interfacial force. The interfacial interaction of reinforced soil involves the bonding force of the fiber-soil interface, the friction between the fiber and the solidified cementitious matter, and the anchoring effect between the crystals on the fiber surface and the soil [36-39].

Fiber content affects the reinforcing effect of fiberreinforced solidified soil primarily by changing the effective contact area and the spatial network structure effectiveness. With increasing fiber content, the effect of three-dimensional network structure is strengthened; the effective contact area of reinforced soil is increased, and the bond force and friction force at the reinforcing fibersoil interface are increased, which produces an enhanced performance at the macrolevel. When the fiber content exceeds a specific value, the uneven distribution of fiber and its local weak surfaces begin to reduce the fiberreinforcing effect, which is macroscopically manifested as the weakened performance. Different PP fiber-reinforced soils show different reinforcing effects with the fiber content changing, which is primarily related to the reinforced objects. The fiber-reinforcing effect is related to the cement content, which is primarily manifested by whether the matrix has larger deformation [20]. When cement content is less than $4 \%$, the cement matrix has lower stiffness and the fiber-reinforcing effect is effectively utilized. Peak strength is increased significantly during triaxial compression. When cement content is greater than $4 \%$, the cement matrix has an increased stiffness. Due to the lower stiffness of PP fiber, the tensile strength of cement soil cannot be adjusted before its very low deformation reaches the peak value $[22,40]$. When fiber is incorporated, soil strength decreases [20, 22, 41]. The overall strength of the solidified soil studied in this test is higher when incorporating fiber.

The effect of fiber length is primarily considered in terms of cohesion and friction. When the fiber embedding depth is small, the effective contact area between the fiber and soil is small, resulting in a smaller interface action between the 


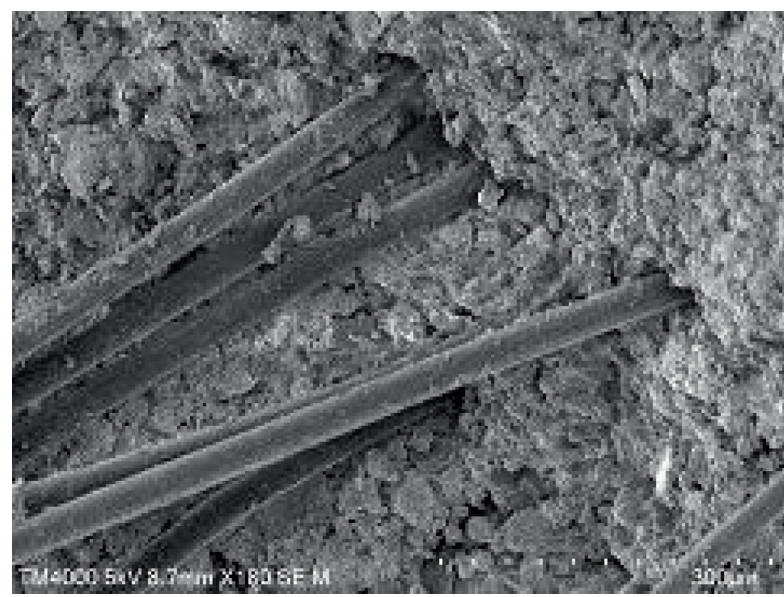

(a)

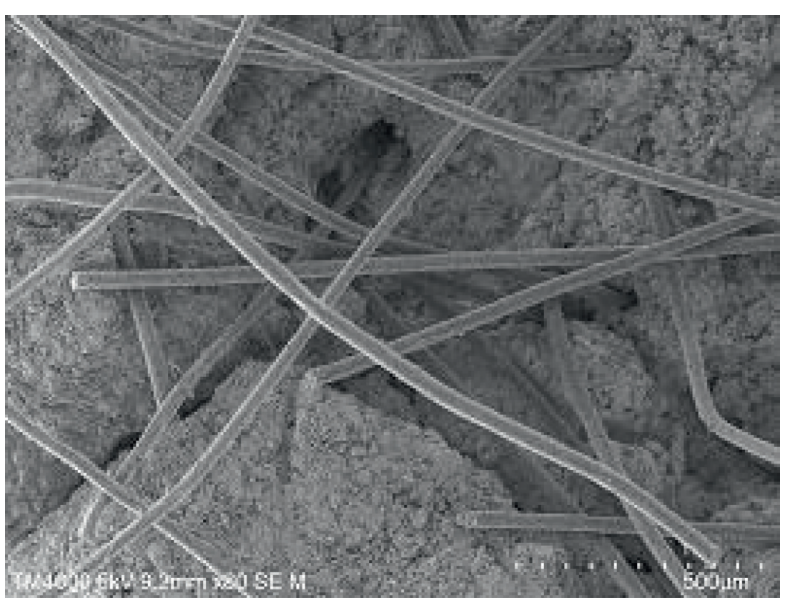

(b)

Figure 13: Fiber-reinforced soil. (a) One-dimensional lacing wire effect (180 times). (b) Three-dimensional network effect (80 times).

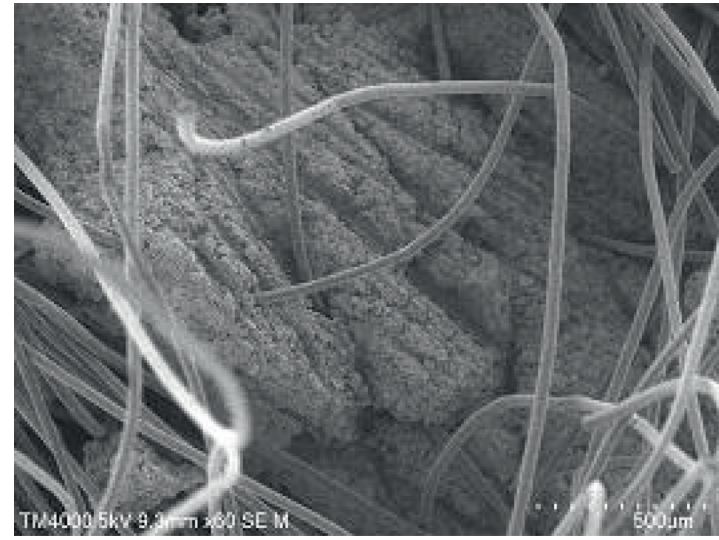

(a)

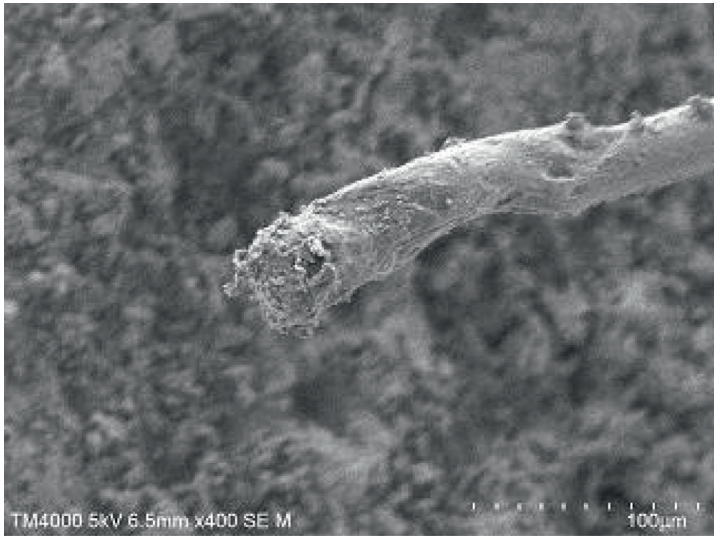

(b)

Figure 14: Failure mode of fiber at the reinforcement-soil interface. (a) Pull-out failure. (b) Tensile failure.

fiber and the soil, and pull-out failure will occur under a larger external load (Figure 14(a)). When the fiber embedding depth is too large, tensile failure may occur (Figure 14(b)). At the same time, fibers that are too long will weaken the dispersion effect of fiber in soil and may even generate weak structural planes, which has negative impacts on soil performance [42]. Therefore, choosing a fiber with an appropriate length has a significant influence on the performance of reinforced soil.

\subsection{Full-Scale Loading Test Results and Analysis}

3.3.1. Change Rules of Resilient Modulus. The resilient modulus of pavement is an important index reflecting pavement bearing capacity [3]. The overall resilient modulus is measured using the bearing plate method (Figure 15). Results indicate that with continuously increasing curing age, the overall resilient modulus increases gradually, with a more rapid increase in the early stage (the age $\leq 7 \mathrm{~d}$ ) and a slower increase in the later stage (Figure 15), which is consistent with the strength requirement of airstrips [43].
When the age is $7 \mathrm{~d}$, the overall resilient modulus of the pavement structure using a cement soil base, solidified soil base, and fiber-reinforced soil base is $242.65 \mathrm{MPa}$, 260.26 MPa, and 290.37 MPa, respectively. The pavement bearing capacity reached a significantly high level on the $7^{\text {th }}$ day. For each curing agent, the resilient modulus of the base pavement structure of fiber-reinforced soil is always higher than those of cemented soil and solidified soil and 10\% higher than that of cemented soil.

\subsubsection{Variation Rules of Stress in Full-Scale Test Section}

(1) Variation Rules of Stress in Full-Scale Test Section under Static Load. With the test carried out according to Section 2.4.2. the variation curves of stress in different structural layers under different static loads are obtained (Figure 16). With increasing static load, the stresses at the bottom of base, subbase, and compacted soil base of each structural section increase and are linearly related to pressure. The maximum stresses of different structural layers all appear in the structural section of cemented soil and those of the bottoms 


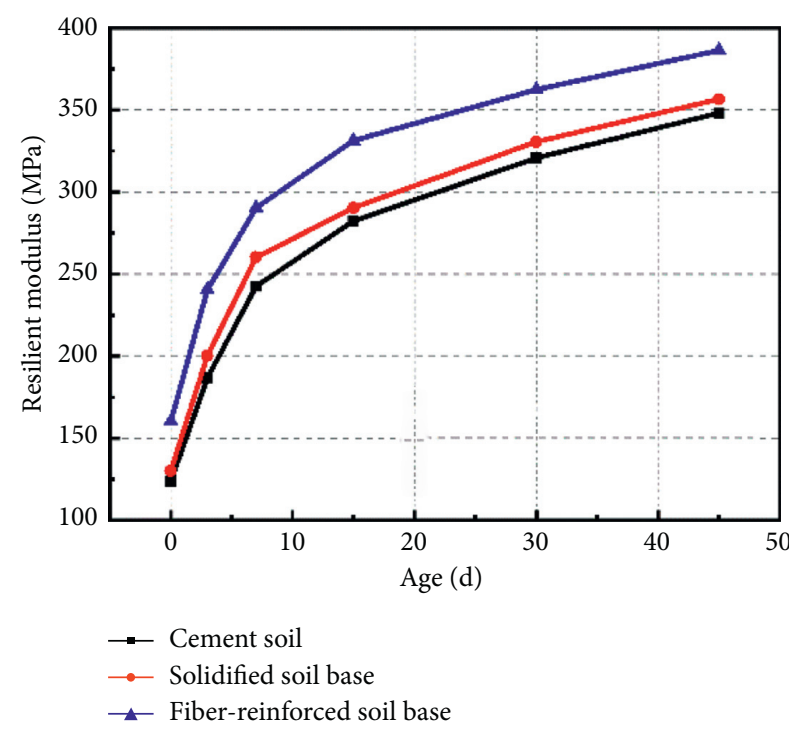

FIGURE 15: Variation rules of resilient modulus of base course with age.

of the base, subbase, and compacted soil base are $0.72 \mathrm{MPa}$, $0.25 \mathrm{MPa}$, and $0.07 \mathrm{MPa}$, respectively. The compressive stress on fiber-reinforced soil is greater than that of solidified soil which is greater than that of cemented soil. Taking the compressive stress at the bottom of base as an example, when the static load is $100 \mathrm{kN}$, the compressive stresses of cemented soil, solidified soil, and fiber-reinforced soil are $0.46 \mathrm{MPa}, 0.43 \mathrm{MPa}$, and $0.36 \mathrm{MPa}$, respectively.

The variation rules of pressure on the subbase and compacted soil base are the same as that on the base. The incorporation of fiber and curing agent increases the rigidity and integrity of the structural layer then weakens the load transferred to the lower structure. After laying GFRP pavement on the surface of the base course, the pressure on the bottom of base course of each structural section decreases from $0.55 \mathrm{MPa}-0.72 \mathrm{MPa}$ to $0.3 \mathrm{MPa}-0.53 \mathrm{MPa}$; the pressure on the subbase course decreases from $0.19 \mathrm{MPa}-0.25 \mathrm{MPa}$ to $0.1 \mathrm{MPa}-0.18 \mathrm{MPa}$; and the pressure on the bottom of the compacted soil base decreases from $0.04 \mathrm{MPa}-0.07 \mathrm{MPa}$ to $0.02 \mathrm{MPa}-0.03 \mathrm{MPa}$.

That is because GFRP pavement can disperse the load. However, the base layer still serves as the main stress layer in this structure. The structural layer composed of GFRP pavement, compacted soil base, subbase, and base course can bear the static load allowing the aircraft to stop in the static state and taxi in the low-speed stable state.

(2) Stress Variation Rules in a Full-Scale Test Section under Dynamic Load.

(1) Dynamic load response of pressure on each structural layer

From the dynamic load response rule (Figure 17) on each structural layer of solidified soil after 5,000 loading times, it can be seen that the variation rules of stress on the pavement of each structural layer are consistent with the loaded waveforms, and the maximum stress on each structural layer under dynamic load is basically equal to that under static load. The dynamic response rules of other structural sections are similar to that of the pavement using solidified soil, both of which show sinusoidal waves. The maximum stress is approximately the same as the stress under static load.

(2) Variation rules on the stress on structural layers with number of loading times

The base course of each structural section still has stronger bearing capacity after 20,000 loading times (Figure 18). The base course can uniformly transmit the dynamic load to the lower structure, without sharply increasing the lower layer stress due to a loss of bearing capacity during structural failure. Results indicate that the typical structural layer of pavement can bear the fatigue load of the aircrafts well, namely, the pavement bearing capacity is good. Under a $100 \mathrm{kN}$ load, the stress level of each structural layer under dynamic load is slightly higher than that under static load, with a difference about $10 \%$. The reason may be that the impact effect of dynamic load on the pavement increases the stress.

3.3.3. Deflection Variation in the Full-Scale Test Section. (1) Deflection Variation in the Full-Scale Test Section under Static Load. As the static load continuously increases, the deflection of the bearing plate edge also continuously increases and has a linear relationship with static load (Figure 19(a)). In the structural section where the pavement is laid, the deflection of the structural section of cemented soil is slightly larger than that of the solidified soil and is larger than that of the structural section of fiber-reinforced soil. Under the same force, the deflection of fiber-reinforced soil is the smallest, indicating that the base course of fiberreinforced soil has the strongest capability to resist deformation as well as greater rigidity. After loading, the deflection of the structural section with pavement slabs is significantly larger than the section without pavement slabs, which may be caused by compaction of the fine sand screed during static loading.

The deflection-static load curve of the bearing plate edge after unloading (Figure 19(b)) shows that plastic deformation linearly increases with increasing static load. Plastic deformation is about 0.3 times the deformation under the corresponding loading force. Deflection of the structural section with pavement slabs is significantly smaller than without pavement slabs. After loading and unloading, there are greater deflection differences in the structural section with pavement slabs, which may be because the fine sand leveling layer is compacted after static loading. Pavement slab bounced when unloaded, but the fine sand leveling layer cannot recover after compaction. Therefore, a void forms between the pavement slab and fine sand screed. When a bearing plate is mounted on the pavement slab, it reflects the variation in pavement slab deflection. There is increased deflection difference of the pavement slab before and after loading. 


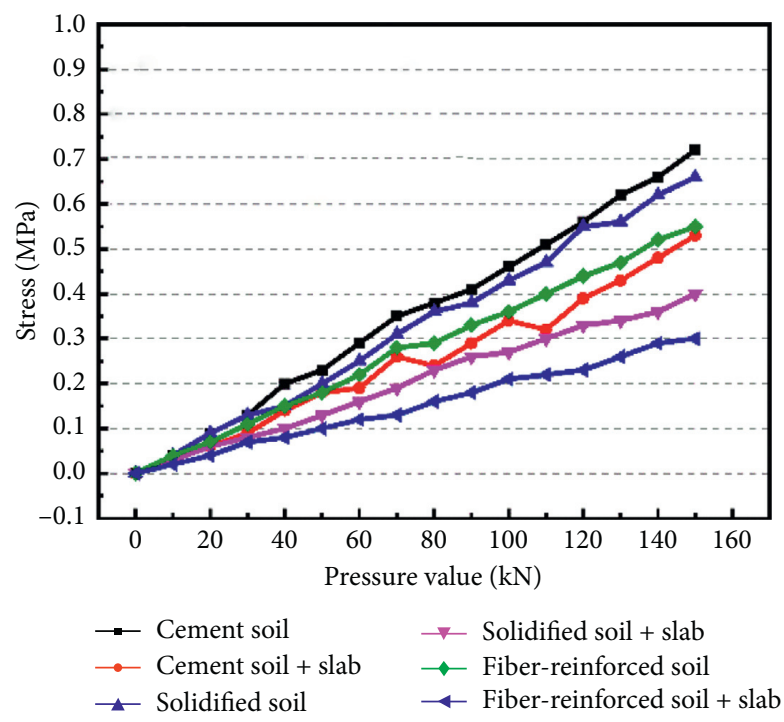

(a)

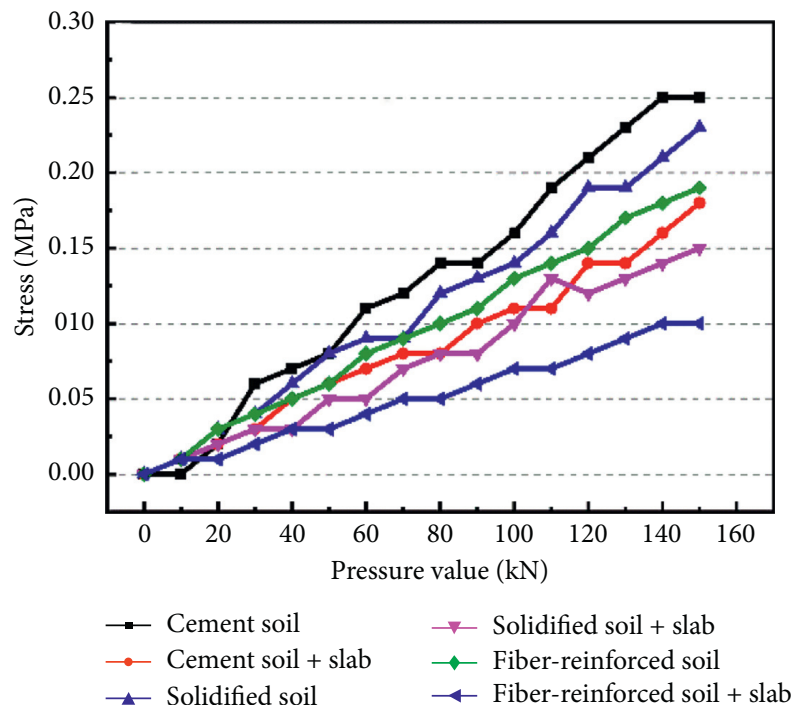

(b)

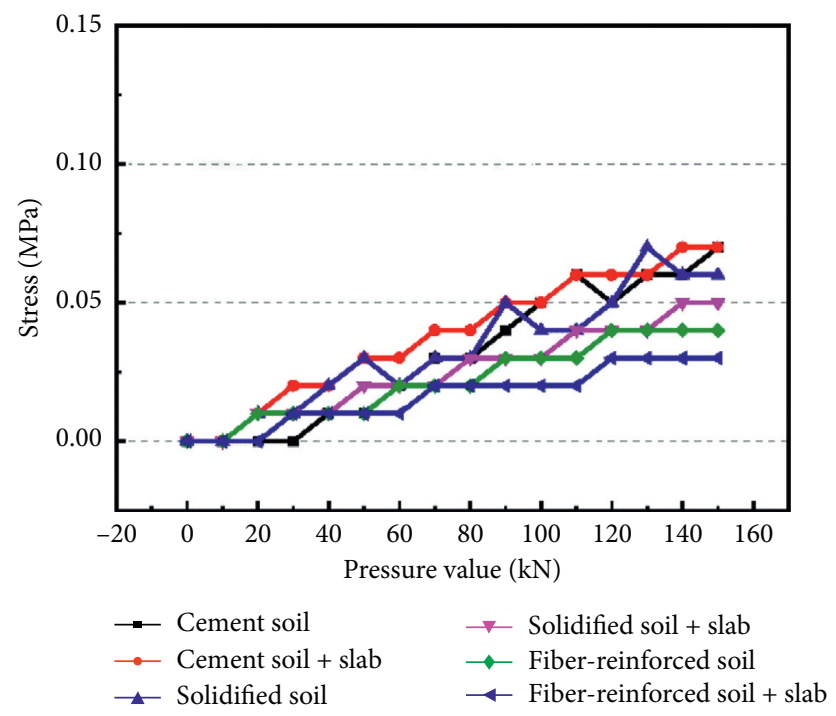

(c)

FIgURE 16: Stress variation rules for each structural layer under static load. (a) Bottom of base course. (b) Bottom of subbase. (c) Bottom of compacted soil base.

(2) Deflection Variation Rules for a Full-Scale Test Section under Dynamic Load. After loading for a certain number of times, the total plastic deformation is defined as the cumulative plastic deformation, and the slope of the two adjacent cumulative plastic deformation curves is defined as the graded plastic deformation. These two indices are used to characterize the degree of plastic deformation in the fullscale test section. According to the research in (1) of Section 3.3.3 the deflection data of the structural layer with GFRP pavement slabs cannot reflect the real plastic deformation of the soil base. In this section, only the deformation of the base course without pavement slabs is analyzed.

In this study, plastic deformation can generally be divided into two stages (Figure 20). In the first stage, the curve of cumulative plastic deformation increases rapidly and the corresponding graded plastic deformation decreases rapidly.
With increasing number of loading cycles, the voids within each structural layer are compressed and the spacing between soil and cement particles is reduced. In the second stage, with increasing number of loading cycles, the cumulative plastic deformation grows in a more uniform manner, and the corresponding graded plastic deformation is relatively stable. At this time, the upper structural layer in the structural section has been completely compacted, and in this case, the deformation of the compacted soil base plays a dominant role. Research indicates that there should be a third stage of pavement plastic deformation. In this stage, the graded plastic deformation increases rapidly, the pavement structure sinks, and cracks increase continuously until failure occurs. After 20,000 dynamic loading cycles, the cumulative plastic deformation of the cement soil base is $1.2 \mathrm{~mm}$; the graded plastic deformation fluctuates around 


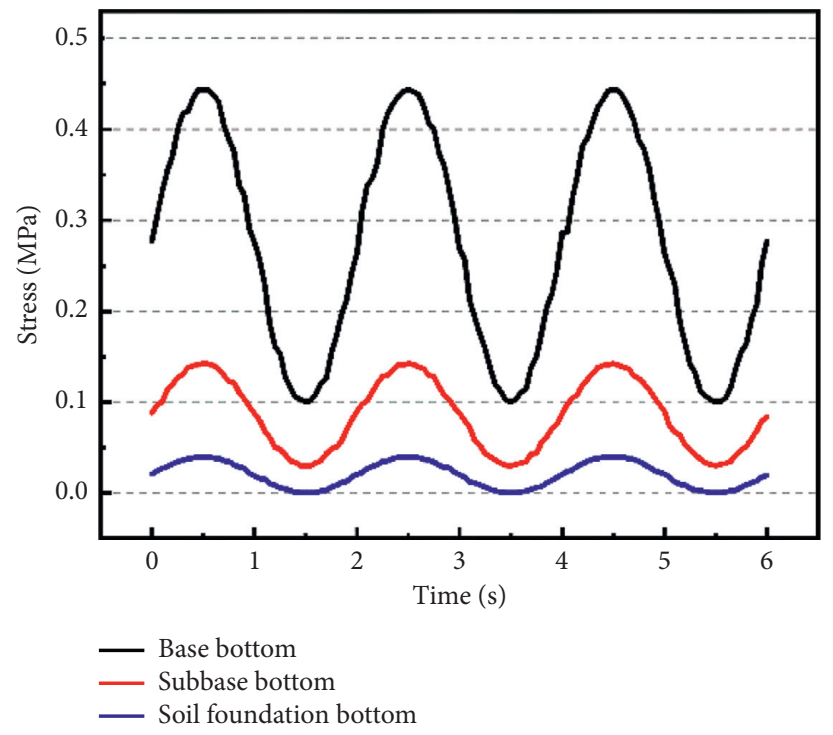

Figure 17: Typical dynamic load response rule of the pavement structure.

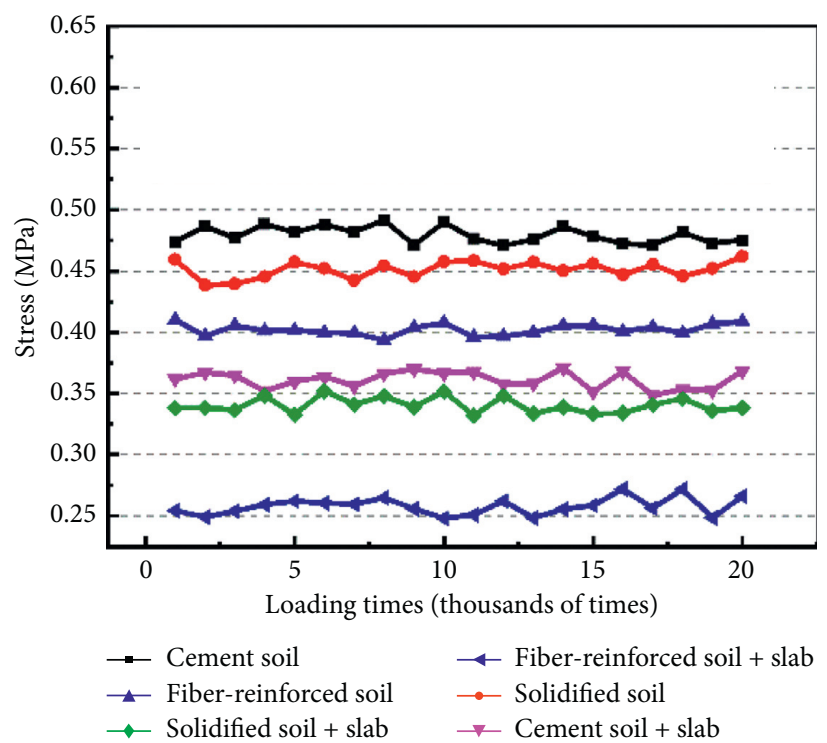

FIGURE 18: Relationship between the maximum stress at the bottom of base course and the number of loading times.

$0.01 \mu \mathrm{m} /$ time; the cumulative plastic deformation of the solidified soil and fiber-reinforced soil base are $0.93 \mathrm{~mm}$ and $0.83 \mathrm{~mm}$, respectively. The graded plastic deformation remains at $0.01 \mu \mathrm{m} /$ time and $0.007 \mu \mathrm{m} /$ time.

In fact, the deflection basin curve is a comprehensive reflection of the mechanical properties and deformation characteristics of each pavement layer during loading [3]. Figure 21 shows the measured curve for deflection basins of different base types after 20,000 loading times, which is an approximate "S-shaped" curve [44]. The deflection at the edge is less than that at the loading center. Taking the base course of cement soil as an example, the deflection $75 \mathrm{~cm}$ away from the bearing plate center is $10 \%$ of the deflection $15 \mathrm{~cm}$ away from the bearing plate center. The reduction rate of the deflection value decreases with increasing the distance away from the load center, which is similar to the results from Liu et al. [3]. Among the three pavement structures, the deflection deformation at each location on the pavement structure of the cement soil base is the largest, and that of each location on the pavement structure of fiber-reinforced soil is the smallest.

(3) Detection of Pavement Damage after Dynamic Loading. After 20,000 dynamic loading cycles, a $60 \mathrm{~cm} \times 60 \mathrm{~cm}$ square was used to select and frame the area of loading points on the base course (Figure 22). In the selected area, there is a long and wide crack in the cemented soil base course, with a crack length and maximum crack width of $800 \mathrm{~mm}$ and $11 \mathrm{~mm}$, respectively. There are two intertwined slender cracks in the solidified soil base. The crack length and maximum width 


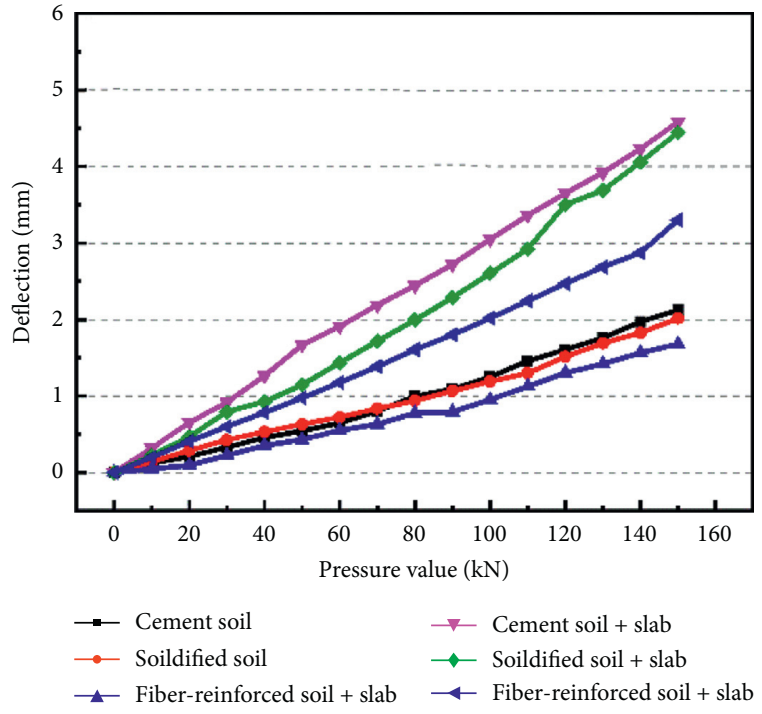

(a)

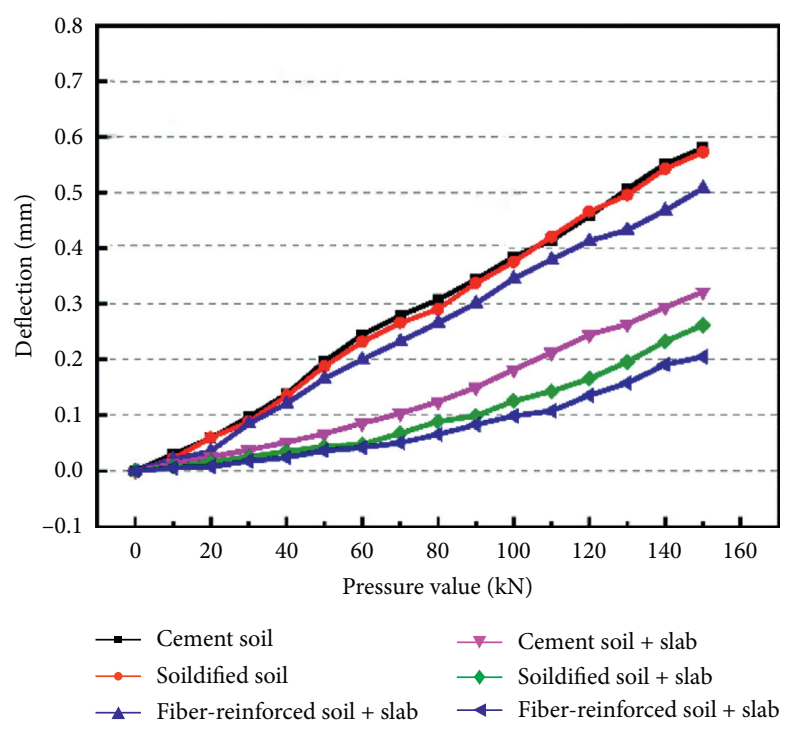

(b)

Figure 19: Variation curves for deflection of bearing plate edge with loading value. (a) After loading. (b) After unloading.

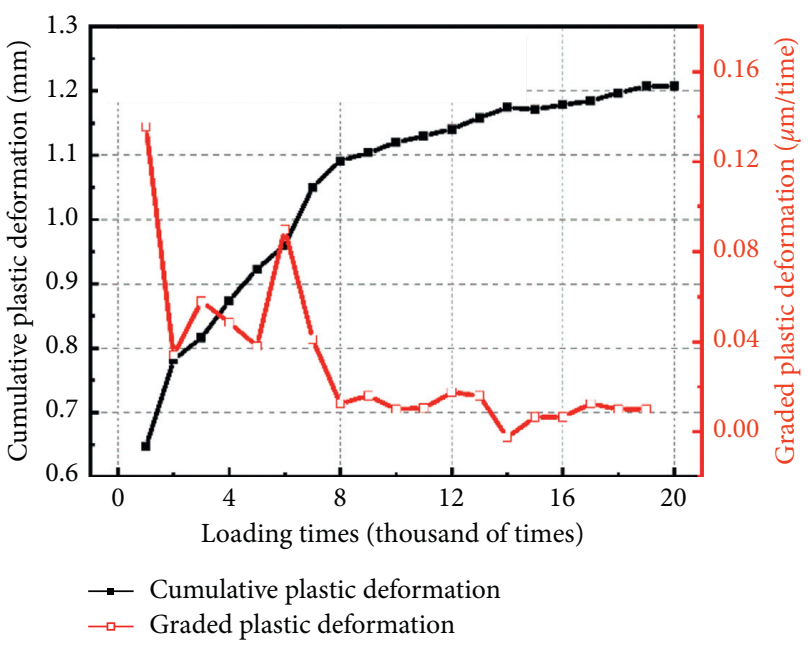

(a)

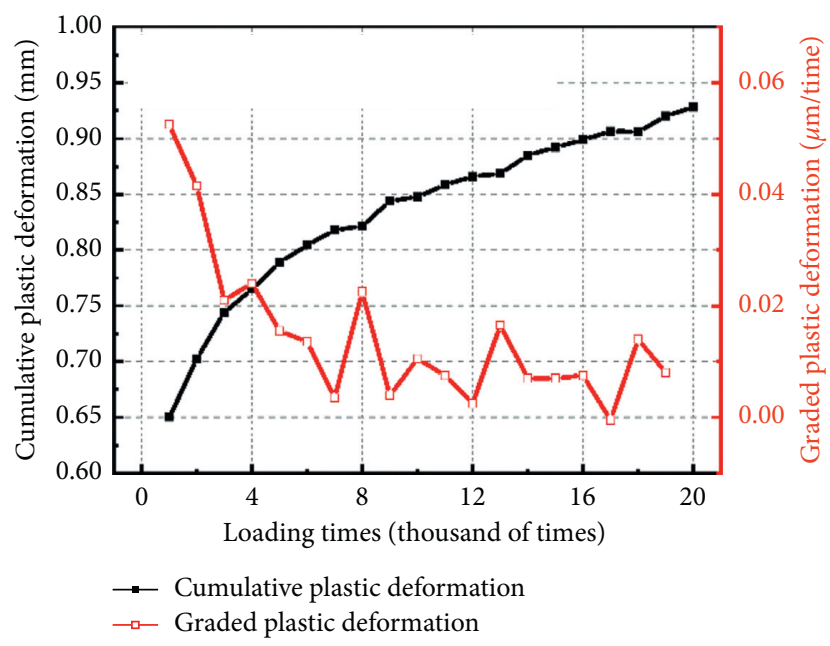

(b)

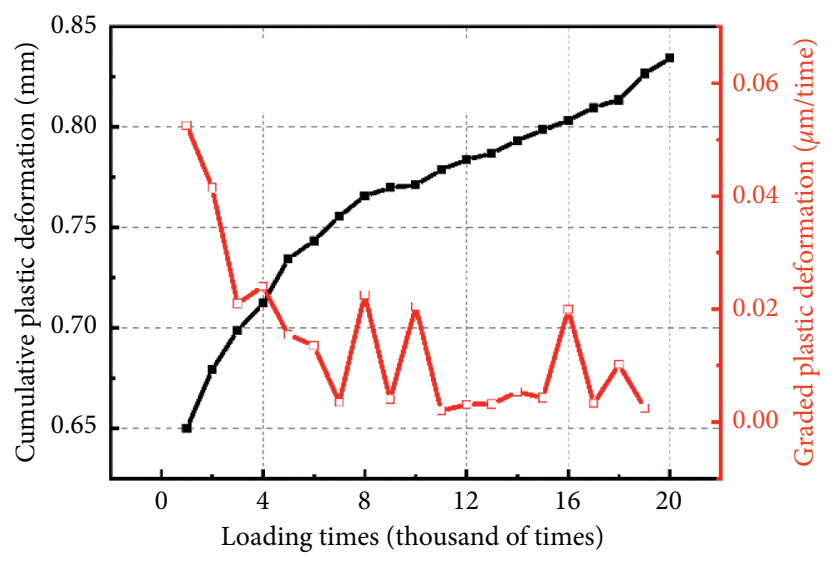

- Cumulative plastic deformation

$\rightarrow$ Graded plastic deformation

(c)

Figure 20: Cumulative plastic deformation and graded plastic deformation of each structural layer. (a) Cemented soil base. (b) Solidified soil base. (c) Fiber-reinforced soil base. 


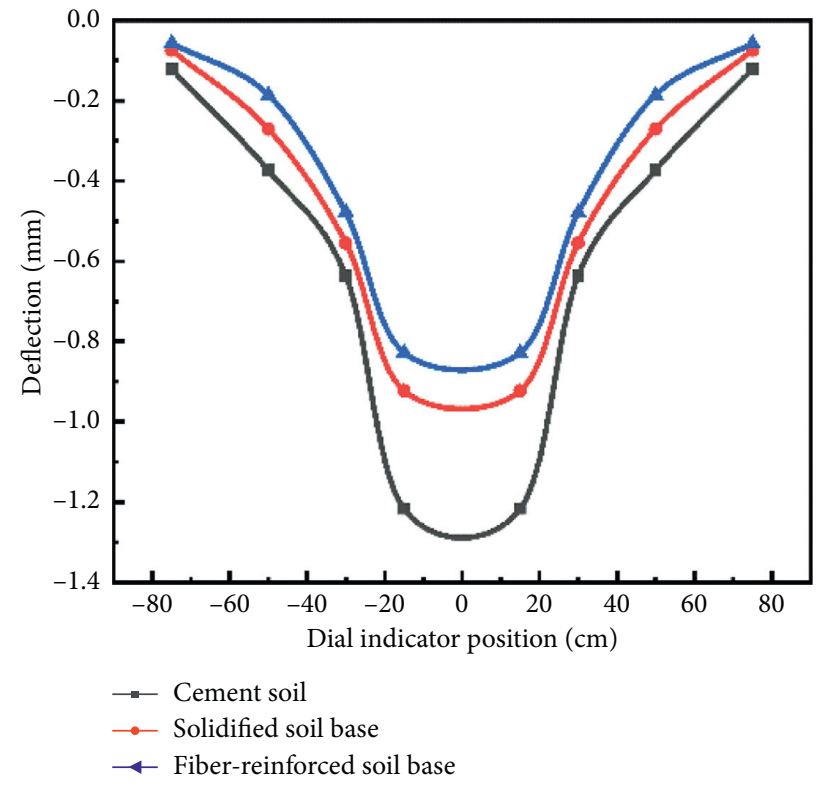

Figure 21: Deflection basins.

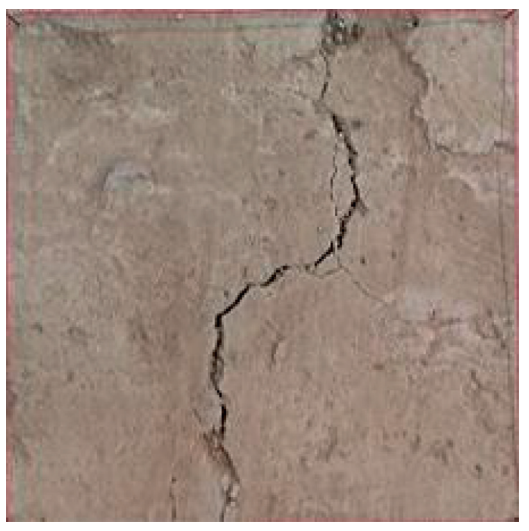

(a)

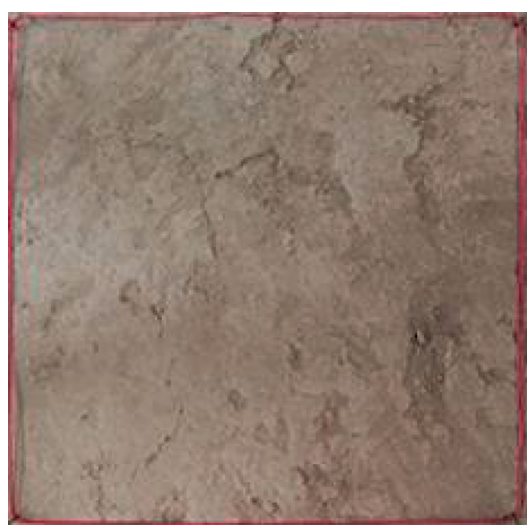

(b)

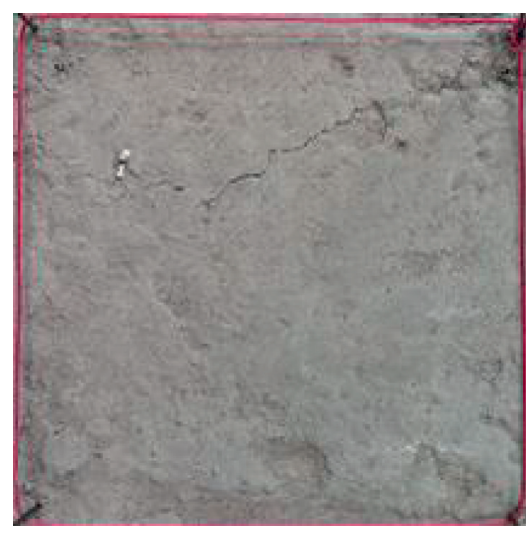

(c)

FIgURE 22: Observed cracks on the surface of base course. (a) Cemented soil. (b) Solidified soil. (c) Fiber-reinforced soil.

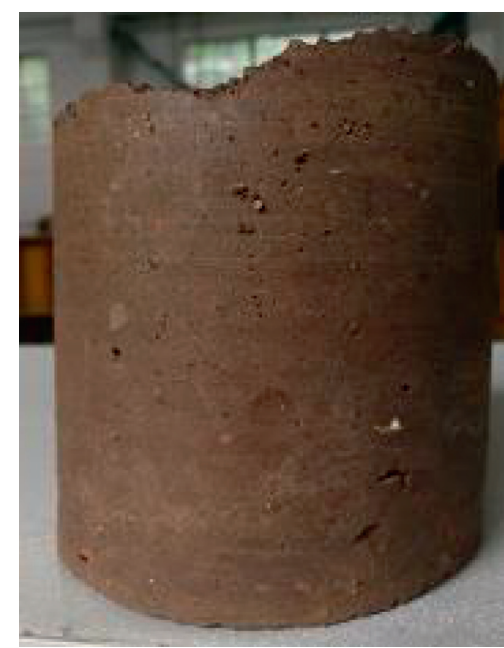

(a)

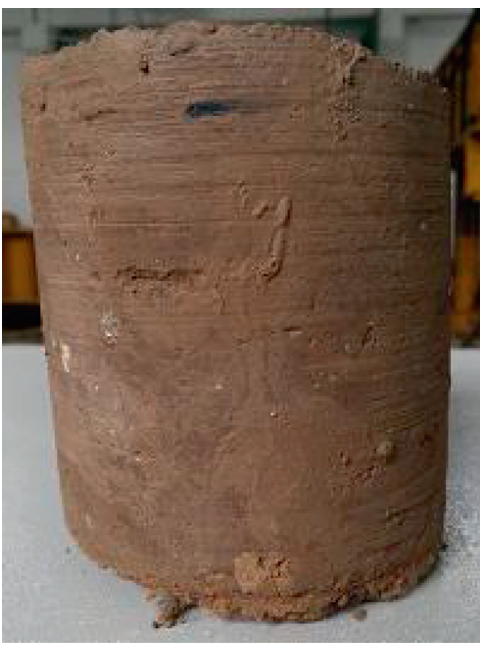

(b)

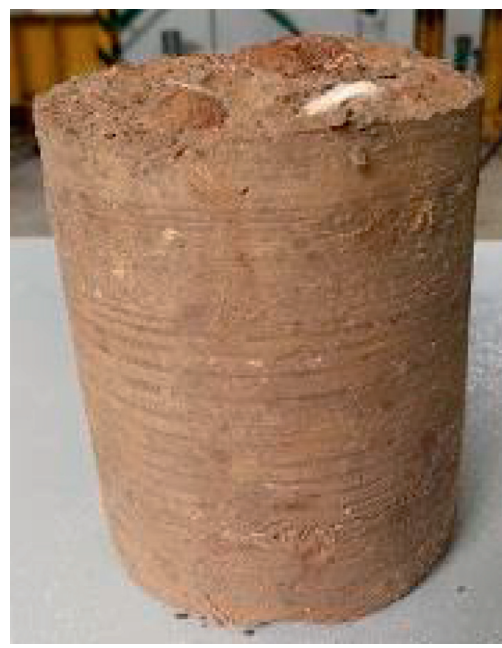

(c)

FIgURE 23: Drill core specimens of each structural layer. (a) Cemented soil. (b) Solidified soil. (c) Fiber-reinforced soil. 
are $750 \mathrm{~mm}$ and $2 \mathrm{~mm}$, respectively. No visible cracks are found on the surface of the fiber-reinforced soil base course, and only a thin and short crack is found near the loading point with a crack length and maximum width of $200 \mathrm{~mm}$ and $1 \mathrm{~mm}$, respectively. The cracking resistance sequence is fiber-reinforced soil $>$ solidified soil $>$ cemented soil. The stress variation of each structural layer under dynamic loading shows that after 20,000 dynamic loading cycles, the pavement structure does not suffer structural damage. The above cracks are primarily generated by drying and external loading. A core sample (Figure 23), collected $30 \mathrm{~cm}$ away from the loading point, is dense and uniform, showing no typical failure characteristics, proving once again that the pavement structure does not undergo structural damage.

\section{Conclusion}

In this paper, the UCS test and STS test were carried out on PP fiber-reinforced soil to study the effects of fiber length and fiber content on soil performance, and the optimal fiber length and fiber content are determined. Using SEM, the reinforcing mechanism of fiber-reinforced soil and the influencing mechanism of fiber parameters on fiber-reinforced soil were discussed and analyzed. Lastly, a full-scale test section was paved, on which static and dynamic loading tests were conducted to verify the bearing capacity and deformation characteristics of the full-scale test section. The following conclusions are drawn:

(1) The addition of fiber can effectively enhance the UCS and STS of solidified soil. The enhancements are related to fiber length and fiber content. Comprehensively considering the performance improvement and economic cost, using PP fiber with the length of $12 \mathrm{~mm}$ and content of $0.3 \%$ is recommended.

(2) According to SEM analysis results, the reinforcing mechanism of fiber-reinforced soil can be summed up as the action of a one-dimensional lacing wire and the action of the three-dimensional network structure. The interfacial action of fiber-soil involves the bonding force of the reinforcement-soil interface, friction between fiber and cementitious material, and anchoring effect of crystals on the fiber's surface and inside the soil. Fibers show two failure modes of pullout and tensile failure.

(3) At the age of seventh day, the overall resilient modulus of the base course of the full-scale section is greater than $200 \mathrm{MPa}$. The modulus indicates that the base course has good bearing capacity and can meet the requirement airstrips. The global resilient modulus of the pavement structure of fiber-reinforced soil base course is $\sim 10 \%$ greater than those of cement soil and solidified soil.

(4) During static loading, the stress of each structural layer is linearly related to the static load, and the GFRP pavement slab will reduce the stress of each structural layer. The structural layer of an airstrip composed of pavement slabs and soil structure layers can more easily bear the load when an aircraft stops or slides at a low speed. After 20,000 dynamic loading cycles, the stress at the bottom of each structural section varies less, indicating that the pavement structure layer still has stronger bearing capacity after 20,000 loading times. The stress on each layer of the pavement structure of fiberreinforced soil base course is the least, exhibiting a higher bearing capacity.

(5) The cumulative plastic deformation and graded plastic deformation of the structural layer show change rules divided into two stages. After 20,000 loading cycles, the graded plastic deformation is stable and the cumulative plastic deformations of the fiber-reinforced soil base, solidified soil base, and cemented soil base pavement structures are $0.83 \mathrm{~mm}$, $0.93 \mathrm{~mm}$, and $1.2 \mathrm{~mm}$, respectively. In addition, each structure suffers no structural damage; the fiberreinforced soil base has the best anticracking effect, and the pavement structure has a better capability to resist fatigue deformation.

\section{Prospect}

Due to the limitations of time and test environment, there are still many deficiencies in this manuscript, which need to be improved in the later research. They are list as follows:

(1) SEM quantitative analysis will be affected by human and objective factors. In the later research, we can explore how to reduce the influence of human factors through intelligent processing of software such as MATLAB.

(2) During the construction of the full-scale test section, it was found that the existing mixing facilities could hardly ensure the fiber was fully dispersed. Therefore, the development of simple and easy construction tools has important engineering and economic significance for the application and promotion of fiber-reinforced soil.

(3) The full-scale test content is limited. This test was carried out under the action of a single frequency and a single dynamic load, which failed to simulate the response characteristics of pavement structures under different aircraft and different taxiing speeds. The loading of 20,000 times is not enough, because the plastic deformation of the pavement structures is small, and there are no obvious failure characteristics. As a result, it is not possible to explore the loading value and times when the pavement structure is caved until shear failure. In the later research, the response characteristics of full-scale test pavement structure under different frequencies, different dynamic loads, and larger loading times should be studied. 
(4) There is still a certain gap between the indoor fullscale test and the real situation, so the field test should be carried out next.

\section{Data Availability}

The data that support the findings of this study are available from the corresponding author upon reasonable request.

\section{Conflicts of Interest}

The authors declare they have no conflicts of interest.

\section{Authors' Contributions}

All the authors approved the manuscript for publication.

\section{Acknowledgments}

This research was supported by the National Nature Science Foundation of China (grant no. 51708550), Natural Science Basic Research Program of Shaanxi (2020JQ-474), and China Postdoctoral Science Foundation (grant no. 2020M671485). These financial supports are gratefully acknowledged.

\section{References}

[1] B.-H. Shi, W.-P. Ning, W. Xu, and S.-R. Dai, "Application of con-aid soil stabilizer in expedient airfield pavement," Journal of Traffic and Transportation Engineering, vol. 13, no. 2, pp. 24-33, 2013.

[2] S. Zhou, L. Cai, X. U. Wei, and G. Cen, "Predictive model of subgrade deformation beneath aluminum sandwich panel," Journal of Southwest Jiaotong University, vol. 51, no. 4, pp. 684-689, 2016.

[3] J. Liu, X. Weng, J. Zhang, X. Li, and L. Guo, "Model experiment of fatigue deformation characteristic of emergency soil airfield pavement," Journal of SouthWest JiaoTong University, vol. 49, no. 3, pp. 412-418, 2014.

[4] C. G.-P. Dong-hua, "Field airfileld runway grassroots quickly strengthening test research," Subgrade Enjineering, vol. 4, pp. 70-72, 2007.

[5] K. Zhang, Q. Wang, L. Chao et al., "Ground observationbased analysis of soil moisture spatiotemporal variability across a humid to semi-humid transitional zone in China," Journal of Hydrology, vol. 574, pp. 903-914, 2019.

[6] K. M. A. Hossain, "Stabilized soils incorporating combinations of rice husk ash and cement kiln dust," Journal of Materials in Civil Engineering, vol. 23, no. 9, pp. 1320-1327, 2011.

[7] R. G. Kochetkova, "Influence of modern stabilizers on improved properties of clayey soils," Soil Mechanics \& Foundation Engineering, vol. 49, no. 1, 2012.

[8] P. Tian, C. Tang, Q. Chen, and L. U. Huifang, "Application of new-type soil stabilizer Q2 in subgrade construction," Agricultural Science \& Technology, vol. 16, no. 2, 2015.

[9] H. Shigematsu and K. Takeda, "Mechanical properties of limestabilized soil in early curing period," Journal of the Society of Materials Science, Japan, vol. 65, no. 1, pp. 22-27, 2016.

[10] X. Luo, H. Hu, Z. Pan et al., "Efficient and stable catalysis of hollow Cu9S5 nanospheres in the Fenton-like degradation of organic dyes," Journal of Hazardous Materials, vol. 396, Article ID 122735, 2020.

[11] R. Ramabhadran, M. R. Sruthy, A. Sharma, and V. Karthik, "Effect of random inclusion of sisal fibres on strength behavior and slope stability of fine grained soils," Iconamma, vol. 5, no. 11, pp. 25313-25322, 2018.

[12] L. C. Dang, B. Fatahi, and H. Khabbaz, "Behaviour of expansive soils stabilized with hydrated lime and bagasse fibres," Procedia Engineering, vol. 143, pp. 658-665, 2016.

[13] S. M. Marandi, M. H. Bagheripour, R. Rahgozar, and H. Zare, "Strength and ductility of randomly distributed palm fibers reinforced silty-sand soils," American Journal of Applied Sciences, vol. 5, no. 3, 2008.

[14] M. Jafari and M. Esna-ashari, "Effect of waste tire cord reinforcement on unconfined compressive strength of lime stabilized clayey soil under freeze-thaw condition," Cold Regions Science and Technology, vol. 82, pp. 21-29, 2012.

[15] D. Wang, H. Wang, S. Larsson, M. Benzerzour, W. Maherzi, and M. Amar, "Effect of basalt fiber inclusion on the mechanical properties and microstructure of cement-solidified kaolinite," Construction and Building Materials, vol. 241, Article ID 118085, 2020.

[16] S. S. Narani, M. Abbaspour, S. M. Mir Mohammad Hosseini, and F. Moghadas Nejad, "Long-term dynamic behavior of a sandy subgrade reinforced by waste tire textile fibers (WTTFs)," Transportation Geotechnics, vol. 24, Article ID 100375, 2020.

[17] S. K. Patel and B. Singh, "Experimental investigation on the behaviour of glass fibre-reinforced cohesive soil for application as pavement subgrade material," International Journal of Geosynthetics \& Ground Engineering, vol. 3, no. 2, p. 13, 2017.

[18] A. S. Soğanc1, "The effect of polypropylene fiber in the stabilization of expansive soils," World Academy of Science, Engineering and Technology, vol. 9, no. 8, 2015.

[19] D. Gupta and A. Kumar, "Behavior of cement-stabilized fiberreinforced pond ash, rice husk ash-soil mixtures," Geotextiles and Geomembranes, vol. 44, no. 3, pp. 466-474, 2016.

[20] A. A. S. Correia, P. J. Venda Oliveira, and D. G. Custódio, "Effect of polypropylene fibres on the compressive and tensile strength of a soft soil, artificially stabilised with binders," Geotextiles and Geomembranes, vol. 43, no. 2, pp. 97-106, 2015.

[21] H. Jiang, Y. Cai, and J. Liu, "Engineering properties of soils reinforced by short discrete polypropylene fiber," Journal of Materials in Civil Engineering, vol. 22, no. 12, pp. 1315-1322, 2010.

[22] N. C. Consoli, M. A. Vendruscolo, A. Fonini, and F. D. Rosa, "Fiber reinforcement effects on sand considering a wide cementation range," Geotextiles and Geomembranes, vol. 27, no. 3, pp. 196-203, 2009.

[23] L. Behak and M. Musso, "Performance of low-volume roads with wearing course of silty sand modified with rice husk ash and lime," Transportation Research Procedia, vol. 18, pp. 93-99, 2016.

[24] G. S. Ingle and S. S. Bhosale, "Development of full-scale laboratory accelerated pavement testing facility: a step toward performance assessment of geosynthetics reinforced pavement," Innovative Infrastructure Solutions, vol. 4, no. 1, 2019.

[25] Ministry of Transport of the People's Republic of China, Test Methods of Soils for Highway Engineering, Ministry of Transport of the People's Republic of China, Beijing, China, 2007.

[26] Ministry of Transport of the People's Republic of China, Test Methods of Materials Stabilized with Inoganic Binders for 
Highway Engineering, China Communications Press, Beijing, China, 2009.

[27] B. Bai and J. Zhou, "The applications and advances of SEM in geotechnical engineering," Journal of Chinese Electron Microscopy Society, vol. 20, no. 2, pp. 154-160, 2001.

[28] M. Wang, H. Chen, B. Yang et al., "Toward an optimal kernel extreme learning machine using a Chaotic Moth-flame optimization strategy with applications in medical diagnoses," Neurocomputing, vol. 267, pp. 69-84, 2017.

[29] Y. Xu, H. Chen, J. Luo, Q. Zhang, S. Jiao, and X. Zhang, "Enhanced Moth-Flame optimizer with mutation strategy for global optimization," Information Sciences, vol. 492, pp. 181203, 2019.

[30] J. S. Yadav and S. K. Tiwari, "Behaviour of cement stabilized treated coir fibre-reinforced clay-pond ash mixtures," Journal of Building Engineering, vol. 8, pp. 131-140, 2016.

[31] A. Tomar, T. Sharma, and S. Singh, "Strength properties and durability of clay soil treated with mixture of nano silica and Polypropylene fiber," Materials Today, vol. 26, pp. 3449-3457, 2020.

[32] M. Mirzababaei, M. Miraftab, M. Mohamed, and P. Mcmahon, "Unconfined compression strength of reinforced clays with carpet waste fibers," Journal of Geotechnical \& Geoenvironmental Engineering, vol. 139, no. 3, pp. 483-493, 2012.

[33] C. S. Tang, B. Shi, and B. J. Wang, "Factors affecting analysis of soil microstructure using SEM," Chinese Journal of Geotechnical Engineering, vol. 30, no. 4, pp. 560-565, 2008.

[34] D. Yiwen, Soft Clay Micro-quantitative Research and its Application, Zhejiang University, Zhejiang, China, 2015.

[35] L. Gao, Q. Zhou, X. Yu, K. Wu, and A. H. Mahfouz, "Experimental study on the unconfined compressive strength of carbon fiber reinforced clay soil," Marine Geotechnology, vol. 35, no. 1, 2015.

[36] C. S. Tang, J. Li, D. Y. Wang, and B. Shi, "Investigation on the interfacial mechanical behavior of wave-shaped fiber reinforced soil by Pullout test," Geotextiles \& Geomembranes, vol. 44, no. 6, pp. 872-883, 2016.

[37] S. B. Chaosheng and K. Gu, "Microstructural study on interfacial interractions betweene fiber reinforcement and soil," Journal of Engineering Geology, vol. 19, no. 4, pp. 610-614, 2011.

[38] T. Chaosheng, B. Shi, G. Wei, F. Chen, and Y. Cai, "Strength and mechanical behavior of short polypropylene fiber reinforced and cement stabilized clayey soil," Geotextiles \& Geomembranes, vol. 25, no. 3, pp. 194-202, 2007.

[39] H.-H. Zhu, J.-H. Yin, A. T. Yeung, and W. Jin, "Field pullout testing and performance evaluation of GFRP soil nails," Journal of Geotechnical and Geoenvironmental Engineering, vol. 137, no. 7, pp. 633-642, 2011.

[40] A. Diambra, E. Ibraim, D. Muir Wood, and A. R. Russell, "Fibre reinforced sands: experiments and modelling," Geotextiles and Geomembranes, vol. 28, no. 3, pp. 238-250, 2010.

[41] M. J. Khattak and M. Alrashidi, "Durability and mechanistic characteristics of fiber reinforced soil-cement mixtures," International Journal of Pavement Engineering, vol. 7, no. 1, pp. 53-62, 2006.

[42] M. Olgun, "Effects of polypropylene fiber inclusion on the strength and volume change characteristics of cement-fly ash stabilized clay soil," Geosynthetics International, vol. 20, no. 4, pp. 263-275, 2013.

[43] T. Tan, L. C. Cai, X. J. Liu, X. L. Chong, and X. U. Wei, "Research on design method of soil expedient airfield runway," Journal of Air Force Engineering University, vol. 13, no. 6, pp. 11-14, 2012.

[44] G. D. Wang and X. Deng, "Geometric characteristic analysis of the dynamic deflection basin," Journal of Southeast University, vol. 29, no. 5, pp. 115-120, 1999. 